\title{
Structural response of French offshore heritage lighthouses
}

\author{
${ }^{1}$ Emmanuel Denarié, ${ }^{2}$ Nicolas Fady \\ ${ }^{1}$ Division of Maintenance and Safety of Structures (MCS-ENAC), Ecole Polytechnique Fédérale de Lausanne \\ (EPFL), GC B3 435, Station 18, CH-1015 Lausanne, Switzerland. \\ ${ }^{2}$ CEREMA - DtecEmf/DT/TSMF/PIE, Technopôle Brest Iroise B.P. 5, 155, Rue Pierre Bouguer, F-29280 - \\ Plouzané
}

Keywords: La Jument, Ar-Men, structural response, dynamic, wave loading, offshore, rock, lighthouses

\section{Summary}

Offshore lighthouses are a remarkable historical heritage often over 100 years old. The management of their ageing is a challenge and requires a thorough understanding of their structural response under wave loading. With this aim in view, the dynamic response of the 'La Jument' lighthouse in the French Iroise sea was characterised in situ, with accelerometers, under the action of a breaking wave, during a winter storm in January 2018. Detailed exploitation of the measurement data complemented by photographic documentation of the same wave event helped determine eigenfrequencies and damping coefficients of the structure as well as the likely orientation of the wave and the position of its crest with respect to the lighthouse tower. The results of these analyses were put into perspective with those of literature and more specifically from a 3D Finite Element Modelling (FEM) of the structural response of the lighthouse under the action effects of breaking waves.

\section{Introduction}

The Iroise sea at the west end of France controls the access to the commercial and military harbour of Brest and is immediately near the shipping lane from the Atlantic to the channel and the North Sea which is the busiest in the world, Figure 1. It is also very busy with commercial fishing almost all year round and tourist sailing activities along the coasts in the summertime. Powerful local tidal currents with treacherous shoals and often extreme sea conditions make it one of the most dangerous zones in Europe for navigation. The Iroise sea has been the theatre of numerous shipwrecks, and several severe oil spills have also taken place there. It has the densest population of lighthouses and marine signalisation structures in France, including several offshore, built on rocks. Even if the widespread use of GPS has made the means of visual navigation (diurnal and nocturnal) less critical for decision-making, these structures remain widely used. Lighthouses at sea present an outstanding cultural and patrimonial value which must be preserved as part of the state's legal obligation to ensure the maintenance of maritime signalisation structures. Further, some of them can be used as laboratories for the insitu determination of extreme wave actions effects on structures in the coastal range, also relevant for the development of offshore energy production systems such as wind tower farms [1-3]. Since 2015, 14 lighthouses of Brittany have been listed 'Heritage Historical Monuments Ministry of Culture' in France, among which 'La Jument', off the coast of Ushant Island, and 'Ar-Men' off the coast of Sein Island, Figure 1b, are subjected to the most severe environments. 

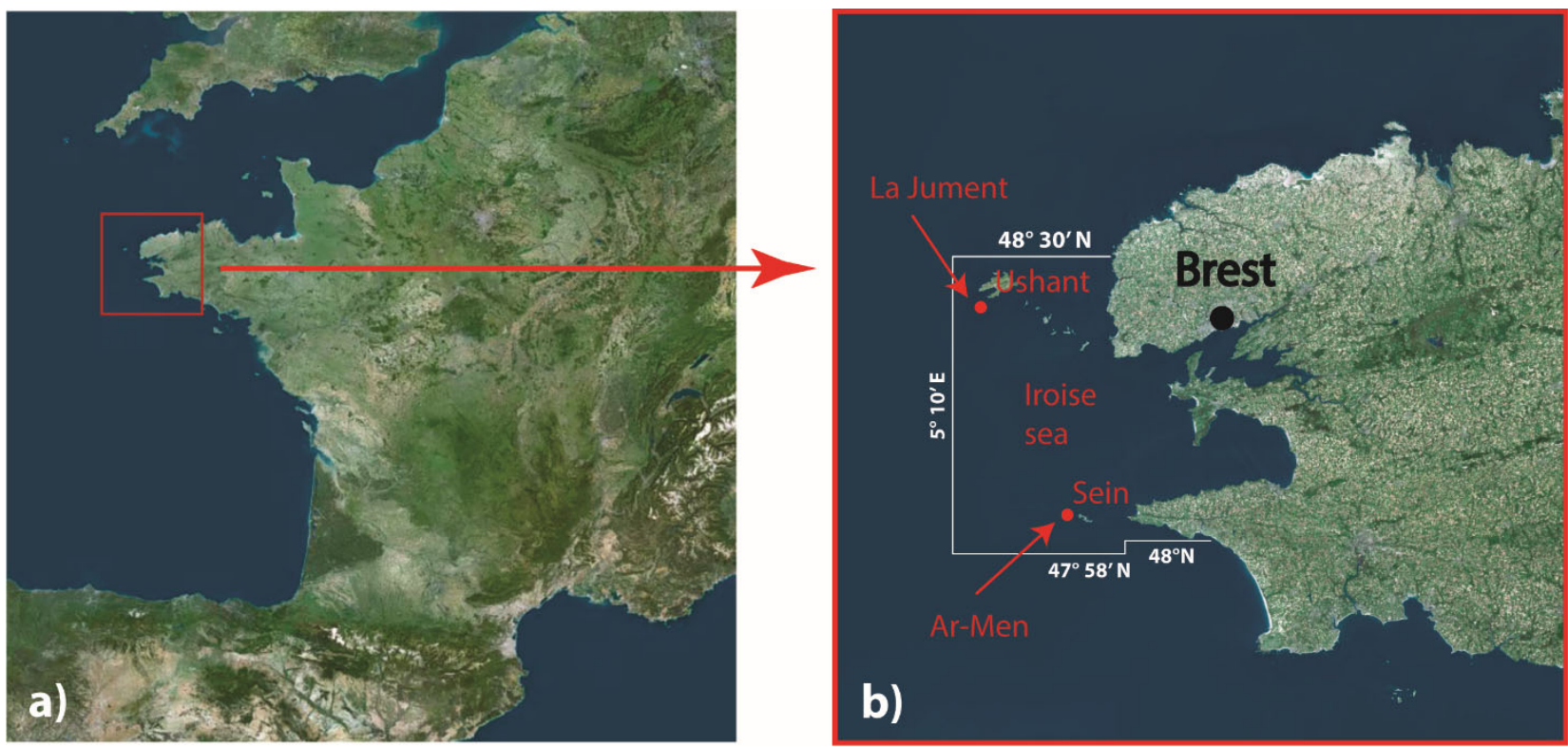

Figure 1. a) Location of the Iroise sea, and b) location of La Jument and Ar-Men lighthouses, maps after https://www.geoportail.gouv.fr/carte

The construction of lighthouses at sea has always been a challenge calling for extraordinary tenacity, courage, and patience. In the most challenging conditions, with very limited access to the location, their construction took years in the $19^{\text {th }}$ and $20^{\text {th }}$ century. These structures, most often over 100 years old, are subjected to extreme environmental loading under the action of strong tidal currents, waves in seas with complex configurations, and corrosive marine climatic conditions. Lerma et al. [4-6] compiled a database of extreme swell events along the French coasts. Highest values were found for western Brittany with $\mathrm{H}_{\mathrm{S}}=16 \mathrm{~m}$. Most recently, McAllister et al. [7] highlighted the effect of crossing seas on the occurrence of extreme events such as the Draupner rogue wave, and Antonini et al. [8] characterized the extreme wave events occurring in the vicinity of the Fastnet lighthouse.

The prediction of action effects of breaking waves on offshore structures and the characterisation of wave loadings remains a challenge, especially for lighthouses on rocks with complex, steep configurations of the sea floor in their surroundings. A review of existing models of action effects of offshore breaking wave impacts on offshore structures can be found in [9-11] as well as in the papers from Filipot et al [1], and Raby et al. [12], in this same issue. Chollet [13] used the SWASH [14] model to determine wave loadings on the Ar-Men lighthouse. Direct measurements of local pressures (amplitude and time history) acting on the structures under wave actions (such as with piezometers) can be undertaken, and the associated structural response can be determined with accelerometer or geophones placed inside the investigated structures and compared with predictions of 3D Finite Element Models (FEM) with similarly applied loadings. The modelling of the structural response of lighthouses requires data on their geometry and on the properties of the materials used. Often, the latter is determined using inverse analyses with 3D FEM models of measurement data of their dynamic response (under ambient vibrations, with seismographs, or under more significant loadings with geophones or accelerometers). Once calibrated, these models can be used to predict the structural response under different loadings such as wave actions.

Characterisation of the structural response and apparent material properties of land-based ancient masonry towers, subjected to dynamic loadings such as earthquakes or motion of bells, can be found in numerous studies in the literature. Gentile et al. [15] determined the fundamental modes of the bell-tower of Monza's cathedral using ambient vibration measurements. The results were used to calibrate the material properties in a 3D FEM model. A non-homogeneous distribution of the modulus of elasticity was used to approximately represent the damaged areas of the tower. Pena et al. [16] studied the dynamic response of the Qutb Minar ancient masonry tower using both ambient vibration measurements and several numerical models including explicit 3D FEM modelling with software DIANA. Material properties were assumed isotropic for the masonry formed of a rubble material made with irregular stones embedded in thick lime mortar. 
Elastic properties were determined from the ambient vibration measurement results, whereas a non-linear tensile response based on a smeared crack model (exponential softening model with a specific fracture energy $\mathrm{G}_{\mathrm{F}}=20 \mathrm{~J} / \mathrm{m}^{2}$ and constant shear retention of 0.01 ) was assumed. A parabolic compressive behaviour was used for all materials. Russo et al. [17] determined the apparent elastic modulus of the cracked "Saint Andrea" Masonry Bell Tower in Venice by means of (1) analysis of accelerometer measurement data under three different types of excitations: ambient vibrations, instrumental hammer and bell motion, (2) 3D FEM simulations, and (3) dynamic analysis using Rayleigh's method. Milani et al[18] studied eight masonry towers from Northern Italy with pushover analyses and non-linear 3D FEM simulations. Damage models with softening laws were used for the tensile response of the masonry. The results from the push-over analyses corresponded with those of the FEM modelling but were slightly less conservative.

Popko [19] investigated the dynamic responses of the Norströmsgrund concrete lighthouse with both 3D Finite element simulations using software Abaqus (with Rayleigh viscous damping), and accelerometer and loading plate data from measurements of loadings induced by drifting ice shelves. The FEM model considered the stiffness properties of the foundation (soil and sand filling the foundation caisson). Good agreement could be achieved between eigenfrequencies derived from measurements and from simulations of the lighthouse. The model of application of ice loadings was discussed on the basis of damping measured and modelled at different levels of the lighthouse. Nord et al. [20] compared, for the Norströmsgrund lighthouse, the dynamic ice loading forces determined (1) by direct measurements of loading plates, and (2) by inverse analysis using 3D FEM with software Abaqus, of accelerations measured in the lighthouse, under ice loading. Good agreement was found between inverse analysis results and the measured ice loadings data.

Loraux [21] and Chollet [13] studied the dynamic structural response under wave action effects of La Jument and Ar-Men on rock lighthouses respectively, using 3D FEM modelling with DIANA [22], explicitly considering the heterogeneous structure of the masonry and its non-linear material properties as well as Rayleigh damping. For La Jument lighthouse [21], elastic material properties were calibrated using inverse analysis of measurement data (velocities) under ambient vibrations, recorded with a seismograph. Non-linear tensile fracture properties (Hordijk [23,24] tensile softening model) were determined based on the analysis of archive documents revealing a core structure of the masonry tower with coarse stone blocks embedded in cement mortar, comparable to dam concrete. For Ar-Men, as no ambient vibration measurement data were available, elastic properties of the masonry were assumed to be similar to those determined for La Jument. The non-linear tensile properties of the masonry were assumed similar to the ones used by Loraux for La Jument for the coarse concrete parts. For the stone masonry parts, the values were determined on the basis of the works from Lourenço et al. [25]. Wave loadings were modelled for both lighthouses on the basis of the works from Morrison [26], Von Karman [27], Goda [28, 29], Wienke et al. [30, 31], Zhou et al. [32]. Rectangular pressure blocks over the height of the structures were assumed in the FEM models, for simplification. One pressure block with a quasi-static triangular wave loading history was imposed on the lighthouse base. Two impulsive loading pressure blocks were applied on the lighthouse towers, one from the top of the lighthouse base until a given height of the tower and another one just above the latter, corresponding to the slamming effect of the wave, both starting after two thirds of the total duration of wave loading. The height of the impulsive pressure blocks was related to the wave height assumed for the calculations. For La Jument [21], the duration of the applied impulsive wave loading was varied between 0.001 and $0.1 \mathrm{~s}$ in a parametric study to determine the most realistic duration of loading according to its consequences in terms of displacements, accelerations and vibration frequency response. The amplitude of displacements increased with increasing loading durations. The frequency of accelerations continuously decreased, and their amplitudes increased for increasing loading durations from $0.001 \mathrm{~s}$ to $0.01 \mathrm{~s}$ and decreased for loading durations from $0.01 \mathrm{~s}$ to $0.1 \mathrm{~s}$. These reversed trends were interpreted in terms of effects on the structure: either affecting serviceability and alarming lighthouse keepers with high, fast accelerations, without significant damage on the masonry, or likely to damage the masonry with large displacements. A very significant change in the structural response appeared when the duration of impulsive loading increased from 0.05 to $0.1 \mathrm{~s}$, with a suddenly predominant first mode that did not correspond to the expected values obtained by ambient vibration measurements. Loraux finally assumed a value of $0.05 \mathrm{~s}$ duration for the impulsive loading in his study [21].

For La Jument, Loraux determined the wave height for his structural analyses based on statistical databases and modelling data of swell [33, 34]. For Armen, Chollet [13] used the SWASH [14] model to determine the wave height, taking into consideration the effect of the bathymetry on the swell derived from the databases [33, 34]. The successive steps of reinforcement of the two structures were modelled under the action of successive wave loading inducing progressive damage to the masonry of the towers. The efficiency of the successive reinforcements was assessed. 
The effect of a hypothetical future reinforcement of the two lighthouses with different techniques among which the application of Ultra High Performance Fibre Reinforced Concrete [35] (UHPFRC) was modelled and discussed. Finally, various types of monitoring were suggested for the two structures.

Trinh et al. [11] studied the dynamic response under wave action of the Eddystone lighthouse. The structure was modelled in 3D with Finite element software LUSAS. Elastic homogenous material properties varying at different parts of the structure were considered. The predictions of the model were compared to measurement data from geophones installed in the structure, during a wave event occurring in winter 2013/2014. Good agreement was found, confirming the hypotheses of wave loading (following Wienke \& Oumeraci [31] models) applied in the FEM model. Banfi [36] studied the dynamic response of the Eddystone lighthouse under wave loading using field testing and small scale laboratory tests on models. A classification of wave loadings of the structural responses was proposed with four types, on the basis of the impulsivity (ratios of peaks) of the signals in the time (velocities) and frequency domains (displacements). Brownjohn et al. [37] determined by testing with accelerometers, under shaker induced forced vibrations, the modal response of six on rock offshore masonry lighthouses along the British coasts. The structures had fundamental modes between 4 and $6 \mathrm{~Hz}$ in a horizontal plane.

This paper introduces first the 'La Jument' lighthouse and its historical background of multiple reinforcements. In a second step, measurement data of accelerometers, under the impact of a wave breaking against the tower are presented and analysed in detail to determine structural response parameters (velocities, displacements, frequency spectra and damping coefficients). Photographic documentation of the same wave is used to determine its likely orientation and the position of its crest with respect to the lighthouse tower. The results of these analyses are finally put into perspective with those from literature and more specifically from a 3D FEM modelling of the structural response of the lighthouse under the action effects of breaking waves.

\section{La Jument Lighthouse}

\subsection{Historical background}

The construction of the 'La Jument' lighthouse lasted seven years between 1904 and 1911, which was the maximum duration imposed by the Charles Eugène Potron legacy who offered to fund the project. The first year of construction, access was possible only 52 hours, then between 150 and 400 hours the following years, for a total of 2037 hours or 85 days over seven years. Initially, the free height of the tower was $29.7 \mathrm{~m}$ from the top of the base. It was reduced to $26.2 \mathrm{~m}$ after raising the base. The original base, completed in 1911, was $3.5 \mathrm{~m}$ lower than the current upper level and was much narrower, almost contiguous to the base of the tower over a large part of its perimeter. The lighthouse is now 118 years old and still resists despite the extreme stresses it undergoes: local configuration of the seabed inducing the formation of breaking waves of more than $20 \mathrm{~m}$ in height, local pressures reaching 20 tonnes $/ \mathrm{m}^{2}$ (18 tonnes $/ \mathrm{m}^{2}$ were back-calculated by Loraux[21] on the basis of the resistance of broken parts of the access door under the impact of a wave). The lighthouse was automated in 1991. The Fresnel lens optics of the lighthouse had a range of 22 nautical miles until the 2014 storms, marking the entrance to the 'Fromveur' channel, south of Ushant, which was the source of many shipwrecks until to the construction of the lighthouse. Since 2015, its range has been reduced to 10 miles with a LED light source. Figure 2 illustrates the progress of the construction works of the base after two years, in April 1906 [38], with the substrate rock on the right. Metal rods anchored in the rock to serve as points of support are visible.

Figure 3 shows the lighthouse with a) execution plan after the engineer C. Ribière [38], b) at the end of construction in 1911 [39], and c) in the 1980s, taken from the boat during a staff rotation of lighthouse keepers (the apparent overhang of the base over the bedrock, on the right side, is a visual artefact of a passing wave and does not exist). Shortly after the commissioning of the structure in 1911, following extreme storms, various reinforcements had to be undertaken to (1) stabilise the structure which exhibited powerful vibrations reported by the keepers and (2) remedy to the cracks found at the base of the tower. The base was progressively widened and raised 3.5 m between 1912 and 1928, and the bottom of the tower was confined between 1917 and 1918 with a reinforced concrete ring that extends down to the level of the old base, $3.5 \mathrm{~m}$ below the current platform level and up to $4 \mathrm{~m}$ from the current platform level. Finally, between 1936 and 1941, three anchors inclined 1/10 to the outside were placed at the foot of the tower to apply stabilisation efforts related to the mass of the tower (Coyne system applied to dams as early as 1931). Of these three anchors, at most 1058 tonnes (probably 2 out of 3 anchors) could be activated compared to the planned $3 \times 1000$ tonnes, designed considering the total weight of the tower of about 4800 tonnes. 
Given the very aggressive salty environmental conditions and doubts about their anchorage, it is unlikely that these anchors still perform any function after more than 75 years.

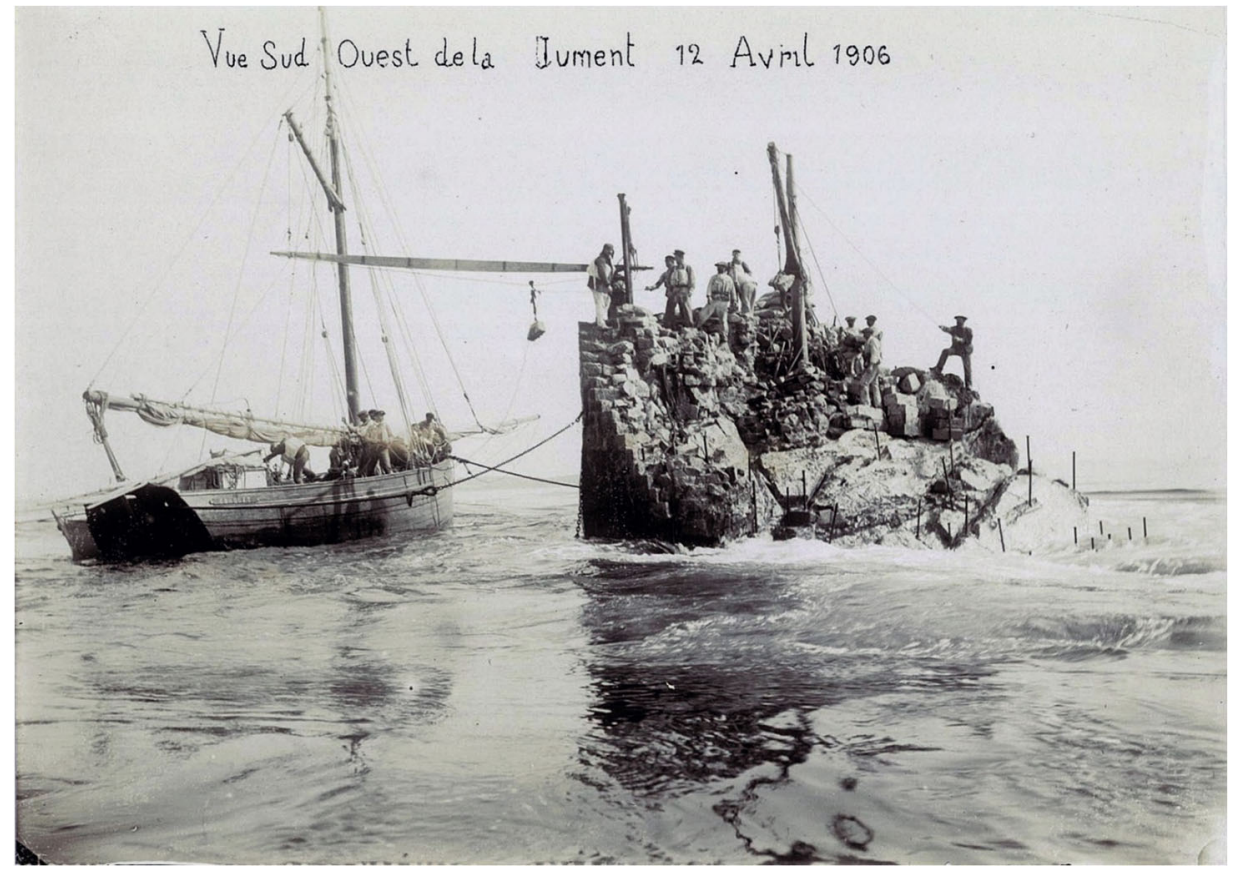

Figure 2. South West view of the construction progress, April 12, 1906 [38].

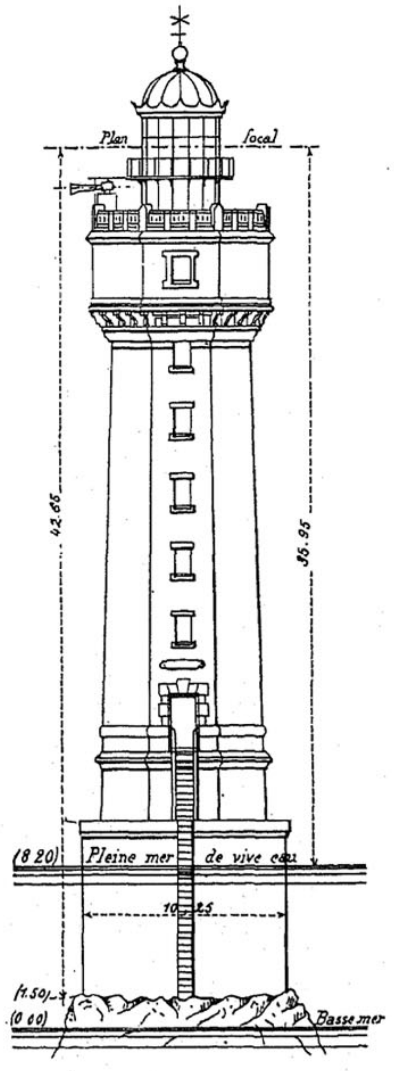

a)

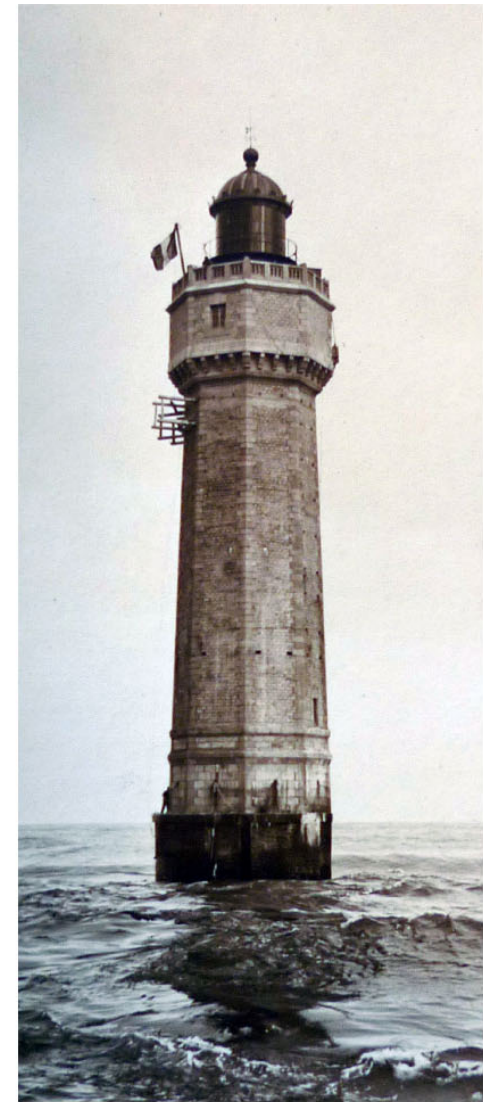

b)

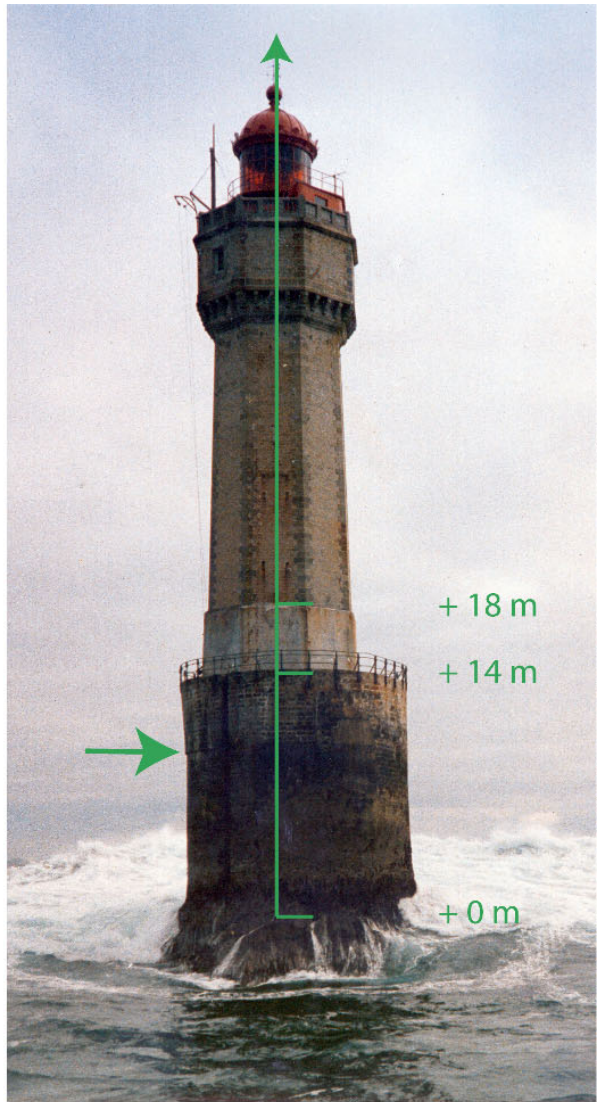

c)

Figure 3. La Jument lighthouse: a) plan after Ribière [38], b) in 1911 [39], c) in the 1980's, seen from the boat approaching for a staff rotation, picture courtesy of George Pennec (the arrow shows the upper level of the original base, before reinforcements).

Phil. Trans. R. Soc. A. 


\subsection{Orientation of the lighthouse}

It turned out to be challenging to accurately determine the cardinal orientation of the lighthouse tower (door) to compare accelerometer data and likely direction of impact of the waves. Detailed investigations of archive documents gave very different orientations of the octagonal tower towards North with variations as high as $20^{\circ}$ for the azimuth of the entry door axis. The best correlation was found between a zoomed in satellite picture of the lighthouse, found on 'Géoportail' [40], and several archive plans with a similar orientation corresponding to an angle of $55^{\circ}$ of the axis of the entry door of the tower with respect to North [41, 42]. The corresponding satellite picture is shown on Figure 4, a) raw and b) with the outlined shapes of the base and tower crown with likely orientation towards North, together with corresponding archive plans, c) and d).

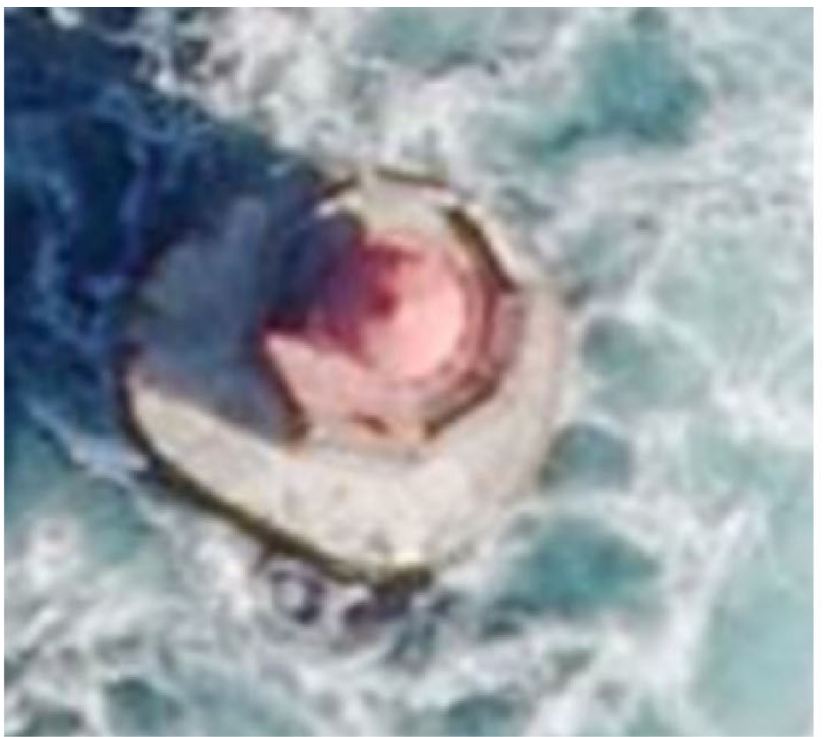

a)

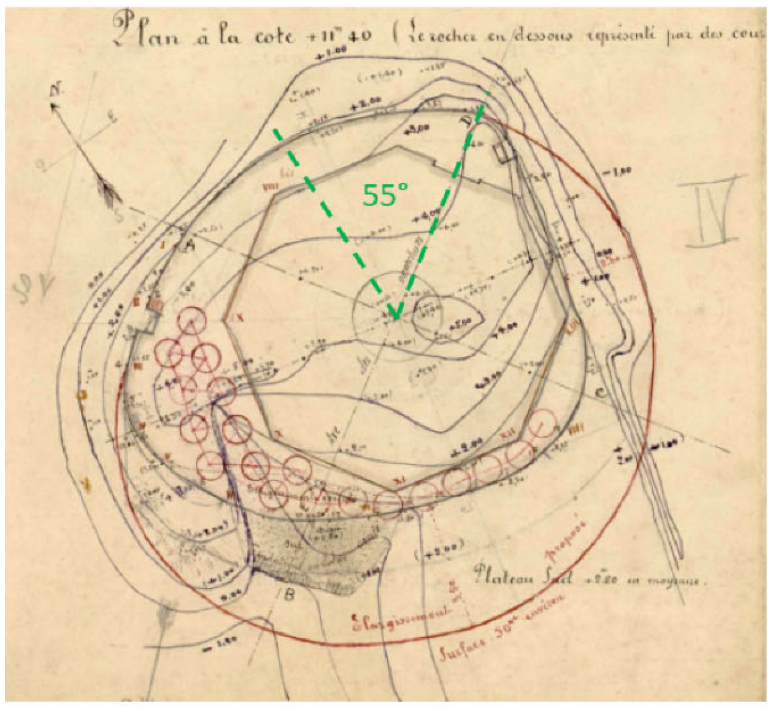

c)

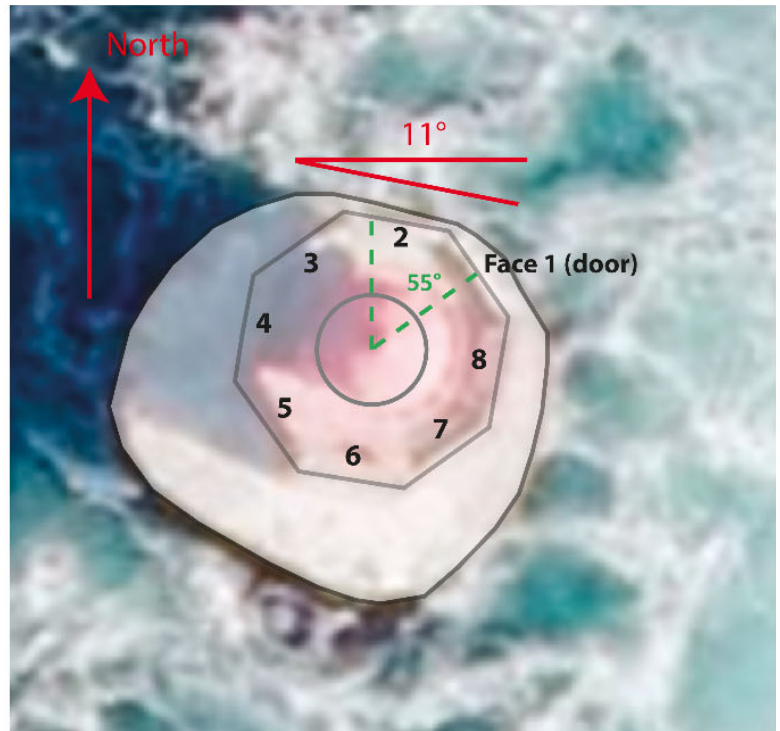

b)

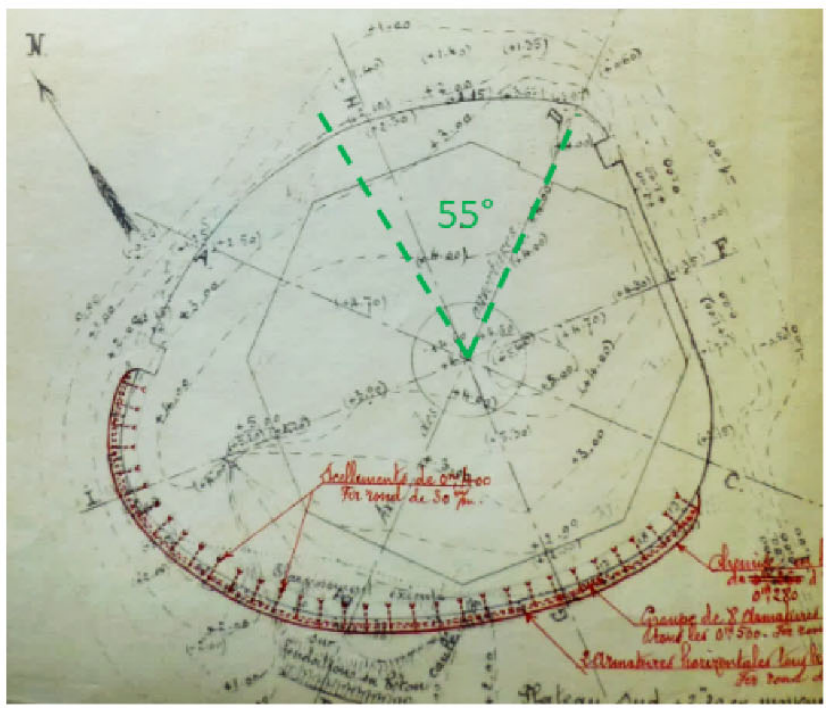

d)

Figure 4. a) Zoomed in raw satellite picture from 'Géoportail' (original scale: 1:266 m), North up, b) same picture with outline of the base and tower crown as well as references of the faces of the octagonal tower and likely orientation towards North, c) annotated archive plan from 1904-1911 [42], d) annotated archive plan from 1918 [41]. Note: North orientation of tower entry door was added on c) and d) for convenience. 


\section{Analysis of monitoring data under wave action}

\subsection{Measurement systems}

The instrumentation of the lighthouse to determine accelerations under wave actions, and characterise these actions has been proposed by various authors [43, 44], and ultimately by Loraux [21] on the basis of his Master's thesis. The structural response of the lighthouse was monitored during winter 2017/2018 using four accelerometers RECOVIB-IAC-A03 ( $\pm 2 \mathrm{~g}$ range) with a sampling rate of $250 \mathrm{~Hz}$, installed in the tower $[2,3]$. Table 1 gives the location and orientation of the measurement axes of the devices. Y-axis is vertical for accelerometers a1, 2, 3, and the z-axis is vertical for accelerometer a4. Accelerometers a1 and a2 are set nearby the windows, on face one as indicated in Figure $4 \mathrm{~b}$ ). Accelerometer a1 is inside the tower whereas accelerometer a2 is set halfway between the two panels of the double window, thus more exposed to local external influences than all other accelerometers. Accelerometer a3 is set inside the tower, on the wall at the corner of faces five and six as indicated in Figure 4b).

Table 1. Location and orientation of the accelerometers. Notes: ${ }^{a} \mathrm{R}$ : front door level, ${ }^{\mathrm{b})}$ with respect to reference level of tides (with respect to LAT - Lowest Astronomical Tide), ${ }^{c}$ with respect to vertical axis of the lighthouse tower.

\begin{tabular}{|c|c|c|c|c|c|c|}
\hline $\mathrm{N}^{\circ}$ & Locationa) & $\begin{array}{l}\text { Height }^{\text {b) }} \\
\text { [m] }\end{array}$ & $\begin{array}{l}\text { Position in } \\
\text { plane } \\
{[\mathrm{m}]}\end{array}$ & $\begin{array}{c}\text { Azimuth of } \\
\text { axes } \\
{\left[{ }^{\circ}\right]} \\
\end{array}$ & $\begin{array}{l}\text { Vertical } \\
\text { axis } \\
\text { positive }\end{array}$ & a \\
\hline a1 & $\begin{array}{l}\text { Kitchen, inside, } \\
\text { close to window } \\
(R+1)\end{array}$ & 20.63 & 2.85 & $\begin{array}{l}x 1=241 \\
z 1=151\end{array}$ & y1 down & $0^{\mathrm{a} 3}$ \\
\hline $\mathrm{a} 2$ & $\begin{array}{l}\text { Sleeping room, } \\
\text { between the two } \\
\text { windows }(\mathrm{R}+4)\end{array}$ & 31.13 & 3.20 & $\begin{array}{l}x 2=235 \\
z 2=145\end{array}$ & y2 down & 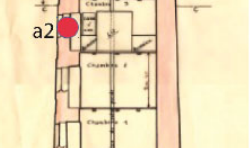 \\
\hline a3 & $\begin{array}{l}\text { Technical room } \\
\text { wall }(R+6)\end{array}$ & 38.75 & 3.50 & $\begin{array}{l}x 3=322 \\
z 3=55\end{array}$ & y3 up & \\
\hline a4 & $\begin{array}{l}\text { Top of optics, } \\
\text { below emergency } \\
\text { light }(R+7)\end{array}$ & 45.65 & 0.20 & $\begin{array}{l}x 4=214 \\
y 4=12\end{array}$ & z4 up & \\
\hline
\end{tabular}

In addition, various measurements to characterise the hydrodynamic environment in the surroundings of the lighthouse were also performed simultaneously, using a Doppler radar and a stereo video system installed at the top of the structure, and a wave buoy (Datawell) and a current profiler (AWAC) located $3 \mathrm{~km}$ West and 300 $\mathrm{m}$ South-West of the lighthouse respectively. Detailed information on these equipment and the analysis of the recorded data can be found in the paper from Filipot et al., in this same issue [1].

During the storm of January 3, 2018, a particular event taking place around $9 \mathrm{~h} 42$ UTC attracted more attention due to the significant height of the wave recorded before breaking on the lighthouse[1]. This event will be referred to as 'wave1' in the following, according to the terminology of the paper from Filipot et al. [1]. The monitoring system installed on the lighthouse helped determine a likely orientation from NW of the approaching wave, within the limits of the range of observation (up to $50 \mathrm{~m}$ ahead of the lighthouse) and a total height of $19 \mathrm{~m}$, with a crest height close to the level of the base platform at $+14 \mathrm{~m}$ above LAT at this location[1]. At the same time, the first author of this paper took a series of pictures of a wave from the 'pointe de Pern' (approximately $48^{\circ} 26^{\prime} 52^{\prime \prime} \mathrm{N}-5^{\circ} 8^{\prime} 26^{\prime \prime} \mathrm{W}$ )[45] while it was directly breaking on the lighthouse. He later found out that another photographer of Ushant also took pictures of the same breaking wave from a different location, 'pointe de Porz Doun' (approximately $\left.48^{\circ} 26^{\prime} 9^{\prime \prime} \mathrm{N}-5^{\circ} 6^{\prime} 42^{\prime \prime} \mathrm{W}\right)[46]$.

The location of the two photographing spots, together with the orientation of the lighthouse and accelerometers axes are shown in Figure 5 with xp1 and xp2 the planes of the two series of pictures taken respectively. 
Considering inaccuracies of 2 minutes in the time stamps of the digital cameras compared to those of the measurement system on the lighthouse, the photographed event is the only one to correspond to the data recorded by the accelerometers.

These two series of pictures provide data that could be used to (1) approximately reconstruct the orientation of the wave as it hit the lighthouse, and (2) guess the likely position of the wave crest in a vertical plane, with respect to the lighthouse tower thanks to a superposition of two images, before and during wave breaking, before the wave spread in multiple jets, eventually reaching the uppermost parts of the lighthouse and almost entirely obscuring it.

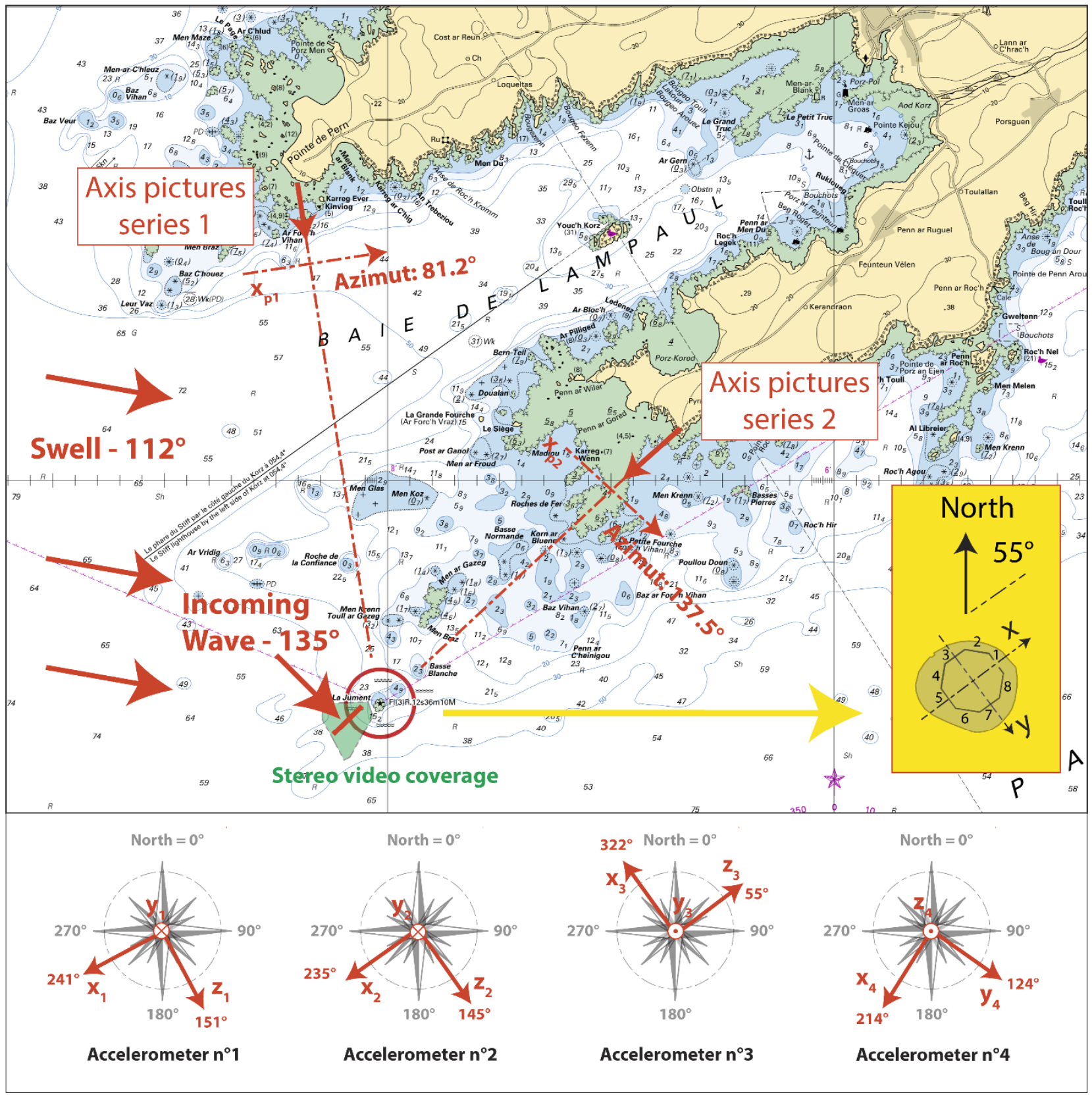

Figure 5. Axes of pictures taken from the Ushant coast with an orientation of the incoming wave and of the accelerometers, base map after SHOM [47].

\subsection{Photographic documentation}

Figure 6 presents the raw pictures from series 1, a) just before the wave hits the lighthouse and b) immediately after, together with c) a superposition of two pictures, one without wave with the lighthouse fully visible and one just when the wave hits [45]. The composited image c) shows that the wave crest corresponds to at least the 
upper level of the reinforced concrete ring around the tower base, significantly higher than the level of the lighthouse platform. The LAT reference level and $+1.27 \mathrm{~m}$ tide level at the time of wave impact are shown for reference. The wave is likely to be hitting between faces 3 and 4 of the lighthouse tower.

Considering the orientation from which the pictures were taken, this suggests an orientation from WNW. As the time stamps of the pictures were not synchronised with the time base of the measurement systems on the lighthouse, their value is not useful and only the time increments between different pictures are mentioned. In what follows the reference time of the first picture of each series will thus be mentioned as ' $t_{i}$ ', without a numerical value.
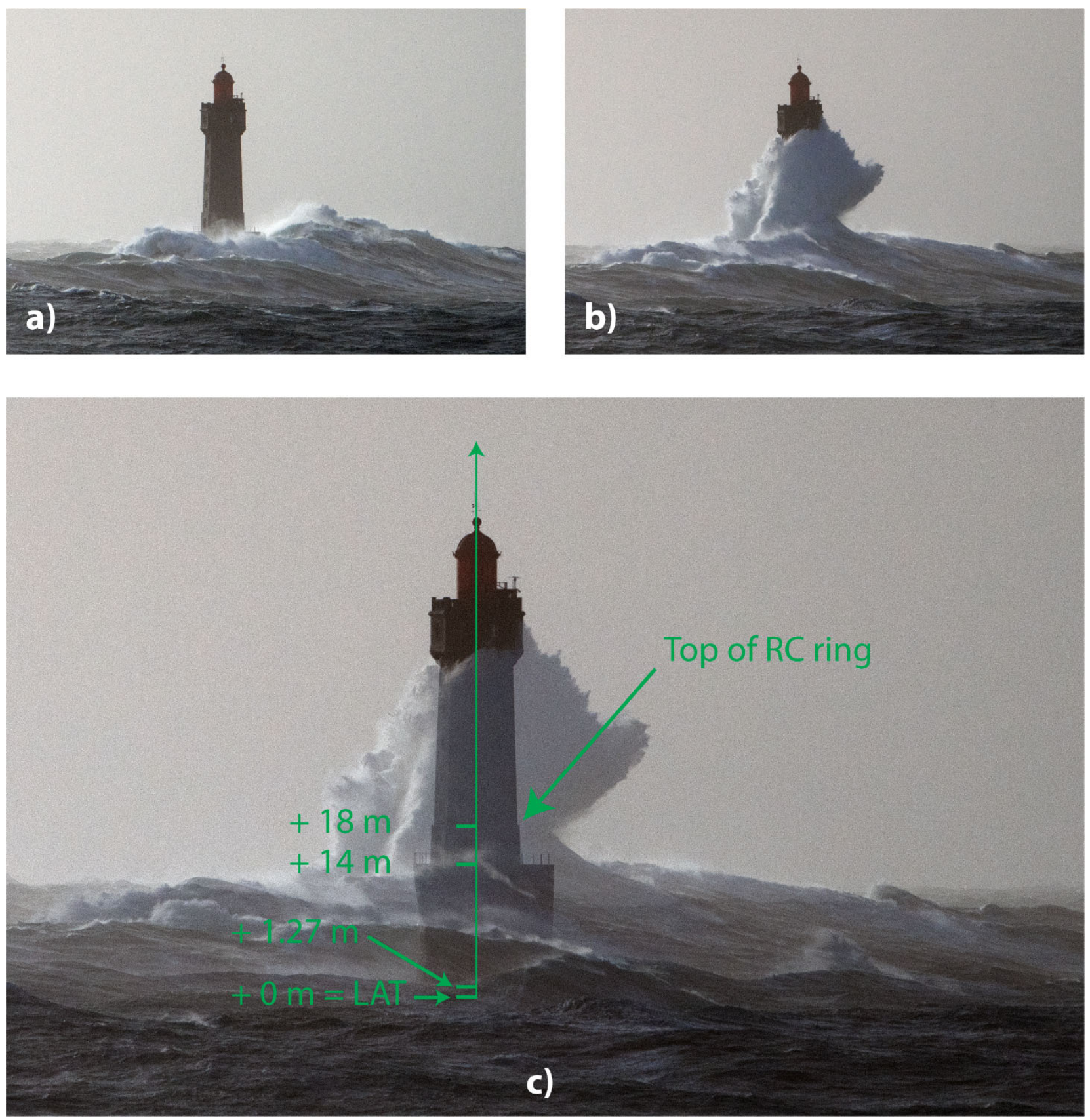

Figure 6. Raw pictures from series 1 , a) $t_{0}$, just before the wave hits the lighthouse and $b$ ) after at $t_{0}+1.32 \mathrm{~s}$, together with a superposition of two pictures c), one with the lighthouse fully visible, and one when the wave hits [45].

Figure 7 presents the raw pictures from series 2 [46]. Figure 7a) confirms that the wave crest corresponds at least to the upper level of the reinforced concrete ring around the tower base, significantly higher than the level of the lighthouse platform. It also shows that the wave is likely to be hitting on face 4 of the lighthouse tower. 
Considering the orientation from which the pictures were taken, this indicates a direction from WNW for the wave. Note that the differences in the colour of the background sky between the pictures of photos series 1 and 2 are due to the orientation of the two different cameras towards the sun.

For picture series 1, the camera was almost facing the sun at that time of the day, biasing the exposure, which required extensive post-treatment to reveal details. Whereas for pictures series 2 , the camera had a much better orientation for optimal exposure.
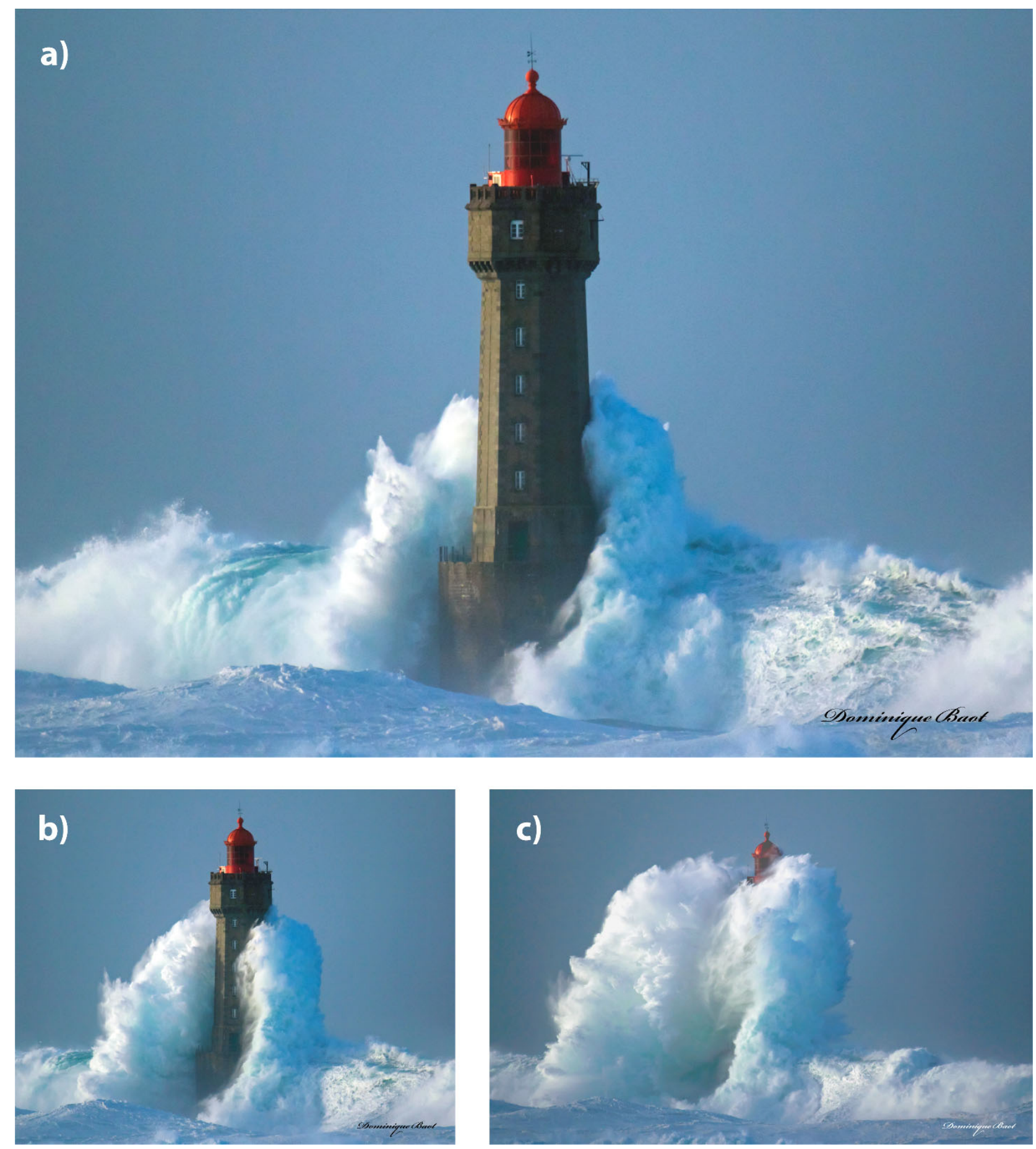

Figure 7. Raw pictures from series $2, a) t_{1}$, b) $\left.t_{1}+0.40 \mathrm{~s}, \mathrm{c}\right) \mathrm{t}_{1}+1.11 \mathrm{~s}$, sequence of images during wave 1 breaking event, courtesy Dominique Baot [46].

Figure 8 illustrates the wave pattern as it develops after initial breaking, seen from the location of series one pictures. Water splashes reach the lighthouse balcony (where the stereo video cameras and radar equipment are installed).

Phil. Trans. R. Soc. A. 

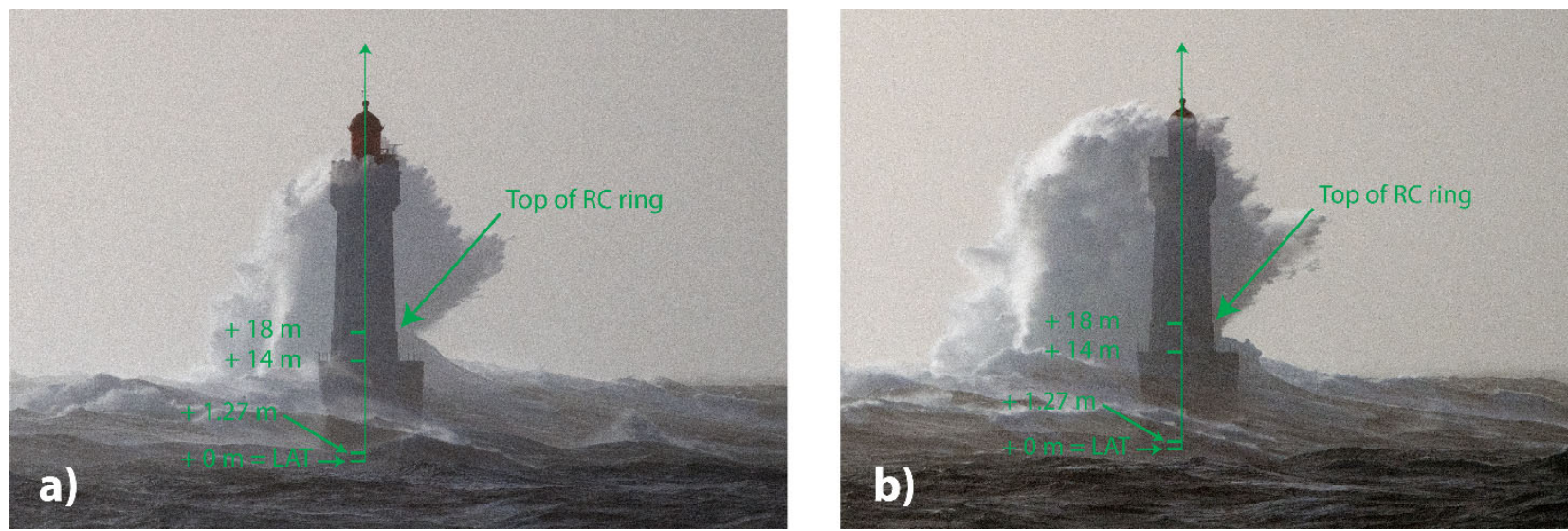

Figure 8. Pictures from series 1 with superposition of a picture, without breaking wave, a) $t_{0}+1.67 \mathrm{~s}$, and b) at $t_{0}+2.33$ $\mathrm{s}, \mathrm{t} 0=$ reference time for picture Figure 6a) [45].

Figure 9 presents the reference picture used for the superpositions, with the lighthouse fully visible, taken 1 minute before wave1 broke. The lowest visible part of the lighthouse base corresponds to the current tide level $(+1.27 \mathrm{~m})$. At that time the effect of atmospheric pressure induced a negligible effect on the sea level $(-0.2 \mathrm{~m})$ [48].

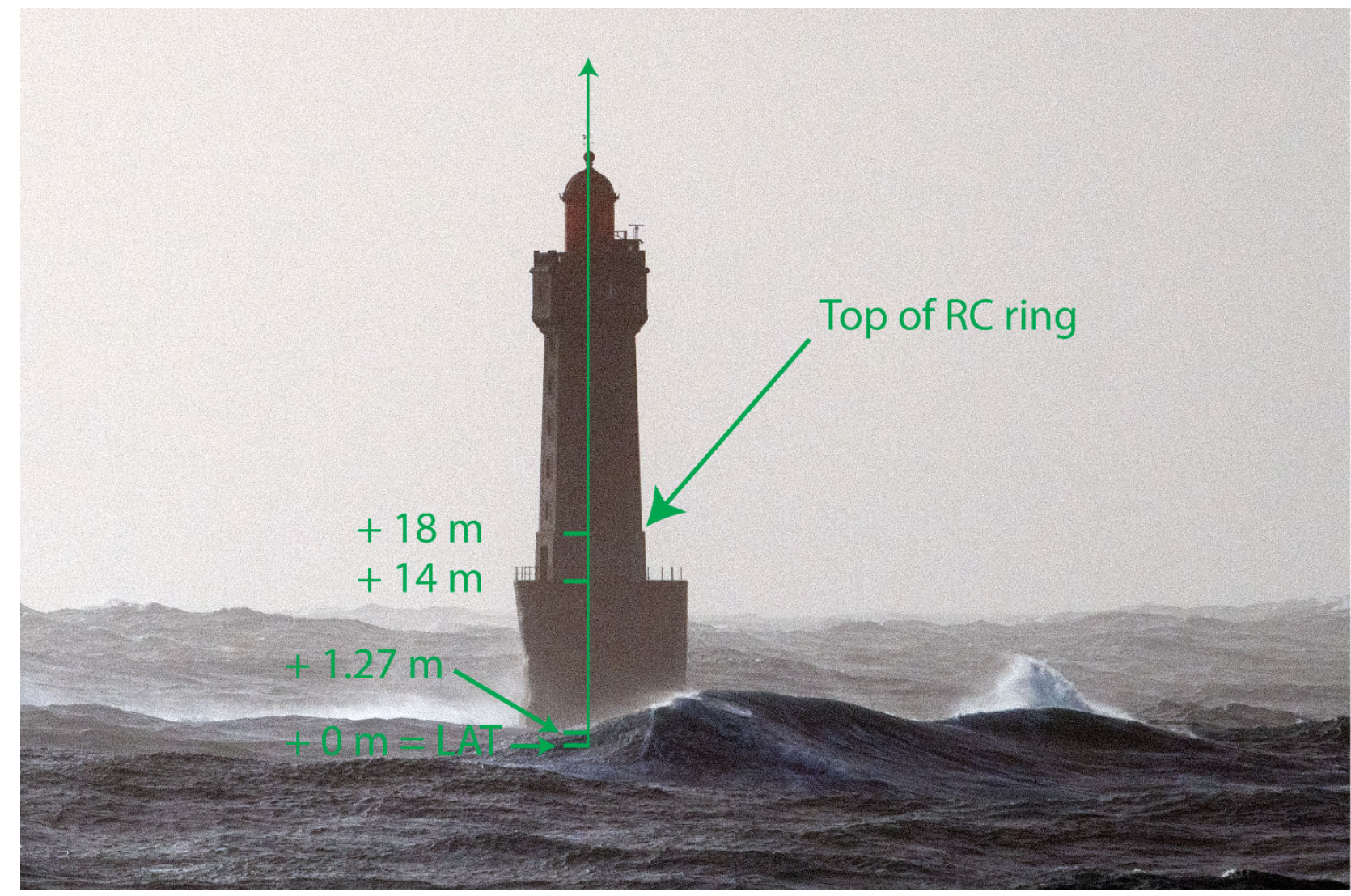

Figure 9. Reference picture from series 1, without breaking wave [45], 1 minute before wave1 hit the lighthouse.

All pictures from series 1 and 2 reveal the highly complex hydrodynamic pattern (spatially and temporally) induced by the wave breaking on the lighthouse or nearby. This can explain discrepancies between the apparent orientation of the wave hitting the lighthouse as shown by the pictures taken from the coast (likely to be coming from $\mathbf{W N W}$, along the direction of the swell) and that determined with the stereo video imaging system installed on the lighthouse tower, after Filipot et al. [1] (coming from NW). 


\subsection{Accelerometer data}

Figure 10 shows the raw data measured by the accelerometers in a horizontal plane, during the event corresponding to wave1, zeroed by subtracting the mean value over the full range of time shown on the plots and detrended [49]. The starting point of the x-axes (709 s of the current recording) corresponds to January 3 , 2018, at 09:42:07 UTC. All x-axes have been reversed to correspond to an orientation going towards the lighthouse tower. The data was filtered with two Butterworth filters [36, 49]: a high pass, order 3 , cut-off at $1 \mathrm{~Hz}$ and a low pass, order 2, cut-off at $30 \mathrm{~Hz}$, leaving the data corresponding to the expected first two eigenfrequencies of the lighthouse, between 3 and $20 \mathrm{~Hz}$. The filtered data is presented superimposed on the raw data in Figure 10. All data from the accelerometers, before and after filtering, clearly show the effect of two distinct events: one starting shortly after $709.5 \mathrm{sec}$ (event 1 ) and one taking place around 710.7 sec (event 2 ). The oscillations related to event $2(\mathrm{a} 2 \mathrm{x}, \mathrm{a} 2 \mathrm{z}, \mathrm{a} 3 \mathrm{x})$ mostly vanish after filtering above $30 \mathrm{~Hz}$. The likely cause of this event remains unclear (mechanical effect of the localised impact of water jets following the main wave impact, and/or electronic artefact).
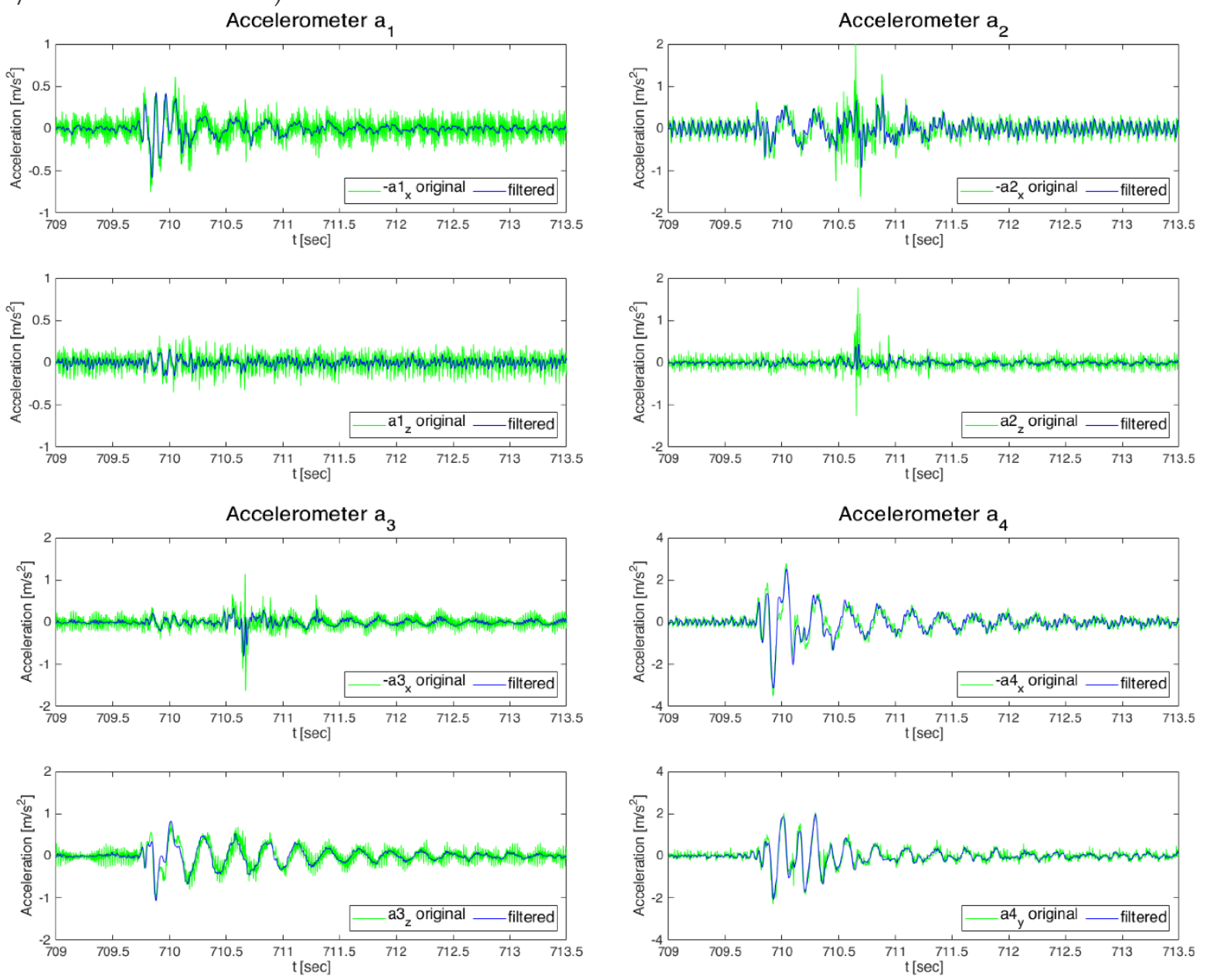

Figure 10. Raw accelerometer measurements (horizontal plane) during wave1 event. Note the use of different vertical scales.

Figure 11a) compares the accelerations measured by accelerometers 1,2,3 directly attached to the masonry of the lighthouse tower, along axes oriented in a nearly similar way: -x1, -x2, z3 (towards North-East) and z1, z2, -x3 (towards South-East), and b) same as a), but for all accelerometers.

The starting point of the x-axes (709 s of the current recording) corresponds to January 3, 2018, at 09:42:07 UTC. Accelerometer 4 is set at the top part of the metallic structure of the optics, at the top of the lighthouse.

This element used to float on mercury when the Fresnel lenses were used. Since 2015, a LED has replaced the Fresnel lenses, and the mercury has been removed. The optics thus rest on the former toroidal mercury container, without being attached to it. 
The accelerations of this part are therefore essential to determine regarding the loads acting on the optics, but only indirectly relevant for the structural response of the masonry part of the lighthouse.
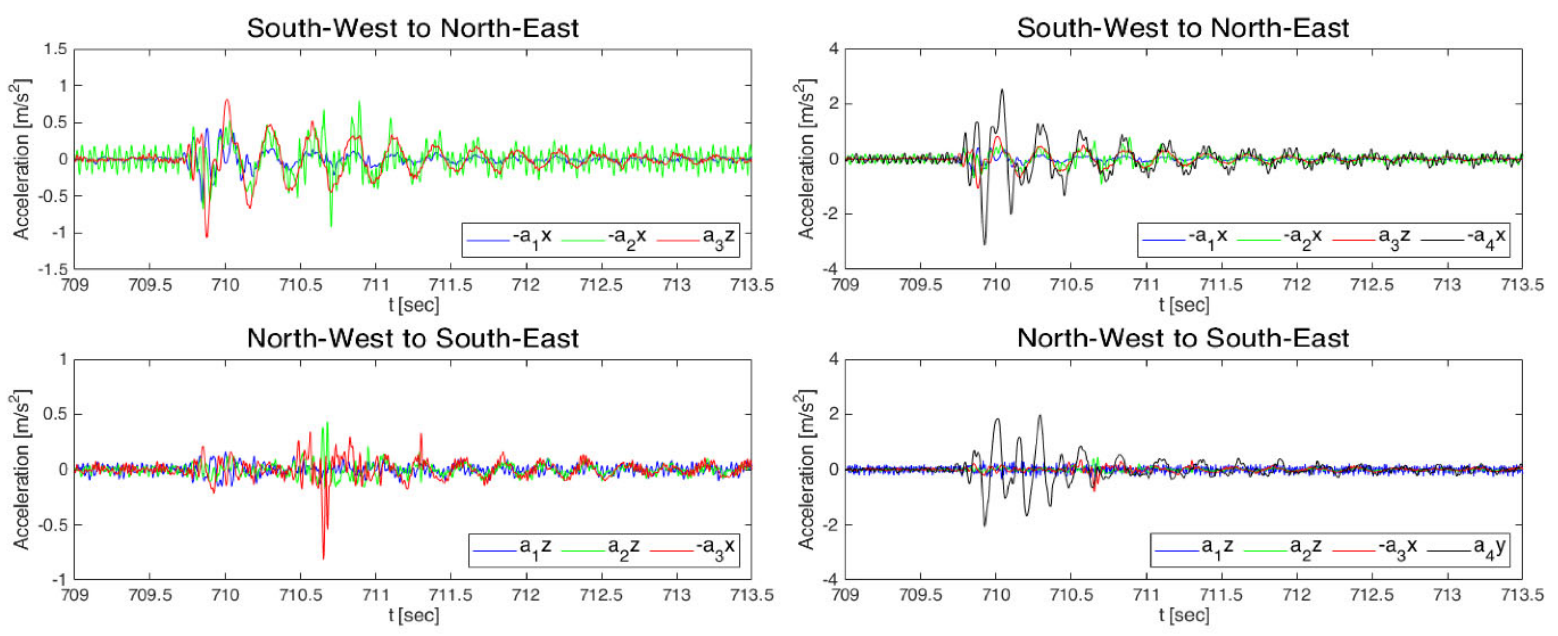

a)

b)

Figure 11. Accelerometer measurements during wave 1 event, a) comparison of values for axes $-x 1,-x 2, z 3$ (SouthWest to North-East) and for axes z1, z2,-x3 (North-West to South-East) accelerometers a1, a2, a3, b) same as a), but for all accelerometers, including a4. Note the use of different vertical scales.

Velocities and displacements were determined by integration, respectively double integration, of the filtered accelerometer data, using a Butterworth high pass filter cut-off at $1 \mathrm{~Hz}$. Figure 12 presents the obtained results. The maximum displacements correspond to +1 and $-2 \mathrm{~mm}$ for a 4 axis y (North-West to South-East direction) and +2 and $-3.5 \mathrm{~mm}$ for the South-West to North-East direction, for a4, axis x. Along the South-West to NorthEast direction, as expected, the velocities and displacements increase with the increasing height along the lighthouse tower vertical axis. Along a North-West to South East axis the trend is less clear.
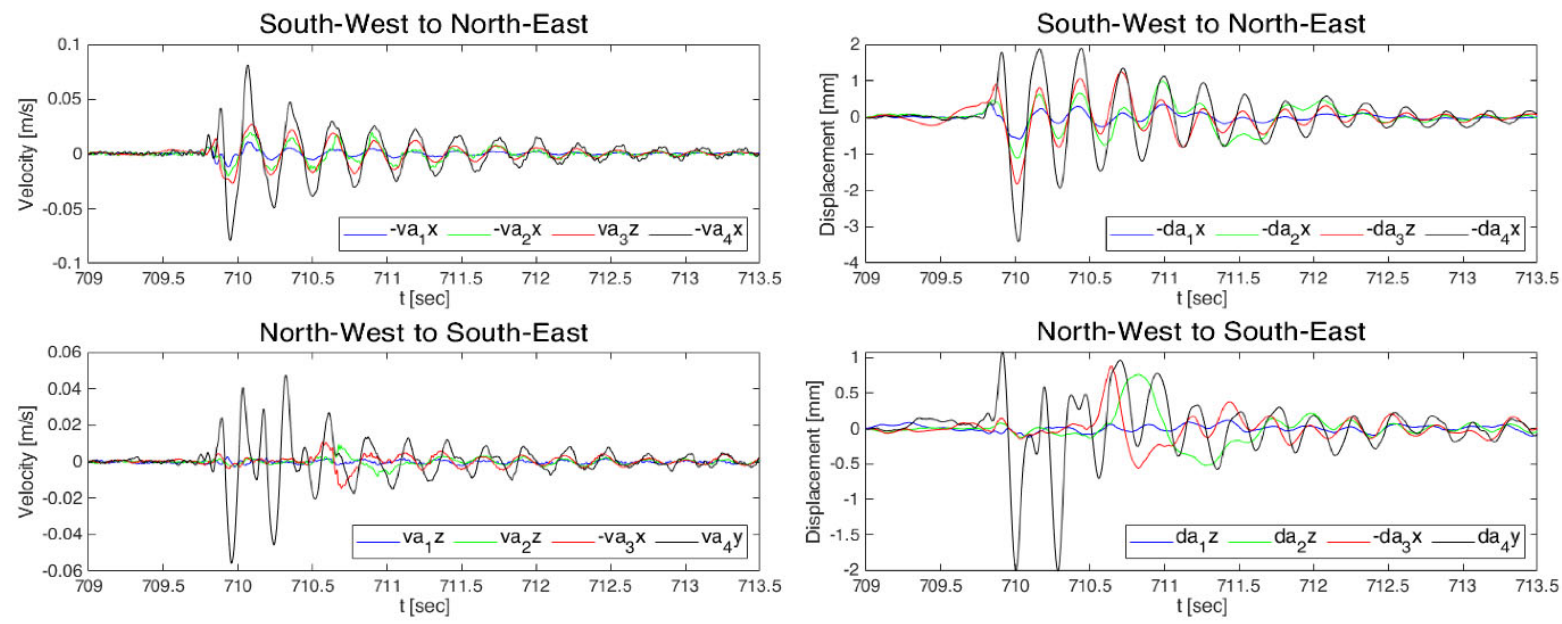

a)

b)

Figure 12. a) Velocities, and b) displacements during wave 1 event, comparisons of values for axes $-x 1,-x 2, z 3,-x 4$ (South-West to North-East) and for axes z1, z2, -x3, y4 (North-West to South-East), data filtered data with order 3 Butterworth high pass filter, cut-off at $1 \mathrm{~Hz}$. Note the use of different vertical scales. 


\subsection{Frequency spectrum analysis}

The measured accelerometer data were analysed after filtering with a high pass order 3 Butterworth filter cutoff at $1 \mathrm{~Hz}$, to determine their frequency spectrum and identify eigenfrequencies. The 'pwelch' averaging algorithm of Fourier transforms, with a Hanning window of 1024 samples was used [50, 51]. Acceleration measurements taken for 5 seconds, immediately before the wave1 event starting at 709 sec, were also analysed with the same procedure for comparison.

Figure 13 presents the results of the analyses for the signals before and during wave 1 event for accelerometer 1 , 2,3 , axes $\mathrm{x}$ and $\mathrm{z}$. The $\mathrm{y}$ axis (rms spectral density) represents the square root of the power spectrum density from the pwelch function, multiplied by the frequency step of the calculation. The range of frequency for which the signals before and during the wave are distinct clearly appears.
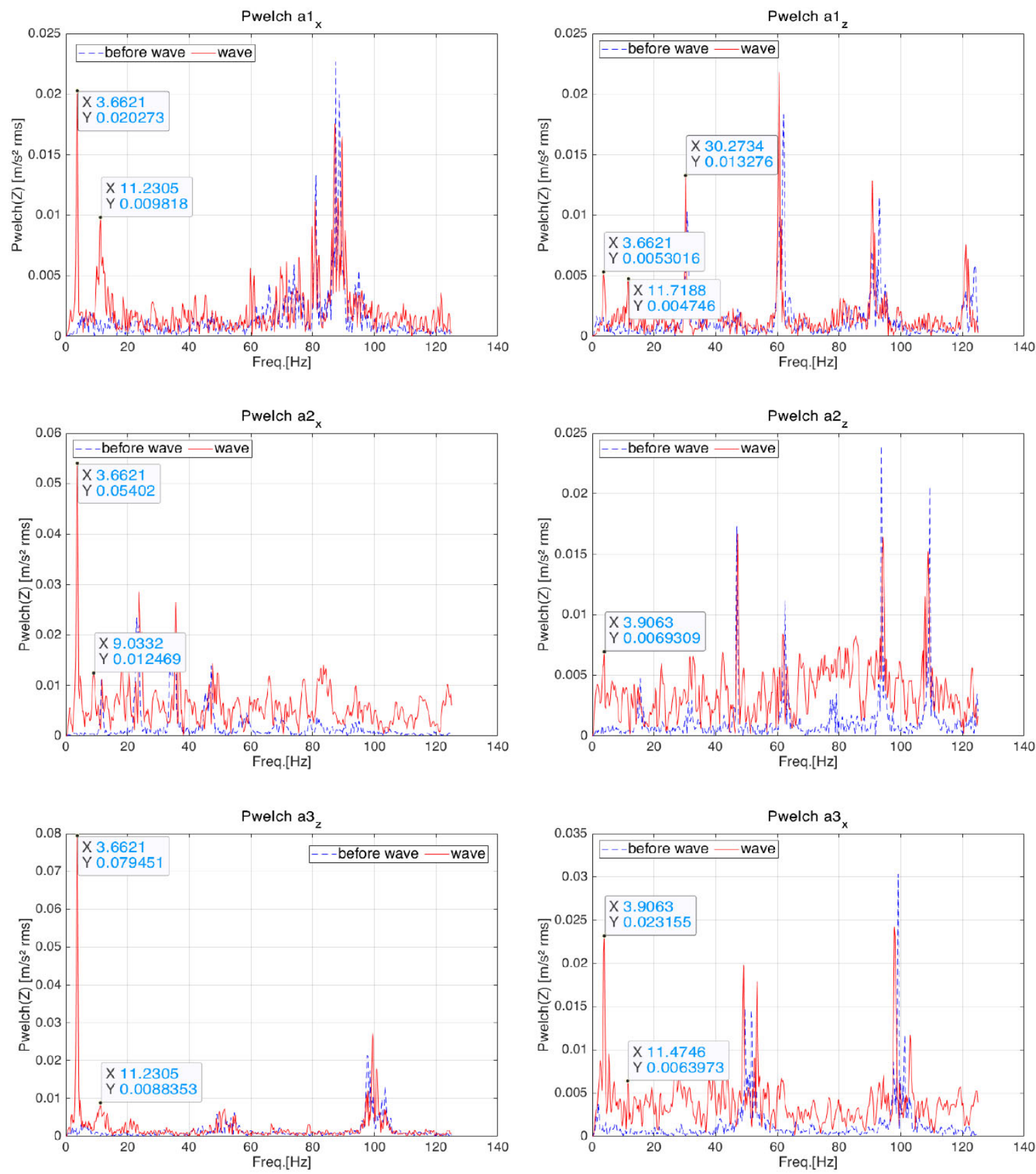

Figure 13. Analysis of accelerometer data for a1, 2, 3 (horizontal plane), rms spectral density vs frequency. Note the use of different vertical scales.

Phil. Trans. R. Soc. A. 
The majority of the accelerometer spectral analyses yielded a first peak at the signal during the wave event a first peak at $3.66 \mathrm{~Hz}$ except for $\mathrm{a} 2 \mathrm{z}$ and a3x which exhibited a first peak at $3.9 \mathrm{~Hz}$. These values correspond to those determined after ambient vibration velocity measurements with a seismometer type GeoSIG GVB-316, performed on site by Loraux [52] in 2013 (average \pm standard deviation of $3.88 \pm 0.09 \mathrm{~Hz}$ for 6 measurements along two perpendicular axes of the lighthouse in plane) in calm weather conditions, and by Chollet [53] in 2014 in calm weather conditions, after the severe storms of winter 2013/2014 (average \pm standard deviation of $3.79 \pm$ $0.05 \mathrm{~Hz}$ for 6 measurements along two perpendicular axes of the lighthouse in plane). They also correspond with the frequencies that could be determined by Loraux[21] using recordings performed in 1935 and 1939 [54] with an oscillograph installed in the technical room, at level $\mathrm{R}+6$ of the lighthouse tower (average \pm standard deviation of $3.77 \pm 0.23 \mathrm{~Hz}$ for the 14 recordings of 1935 and $3.34 \pm 0.42 \mathrm{~Hz}$ for the 9 recordings of 1939). One can notice a slight decrease of $2.3 \%$ of the first frequency peak of the structure, from 2013 to 2014 after severe storms, for measurements in calm conditions, with the same seismograph. In comparison, the measurements with the accelerometers, during a wave loading action show a value $3.4 \%$ smaller than that measured in 2014 . This difference is not significant considering the difference of accuracy of the equipment used in 2013/2014 (seismograph) and 2018 (accelerometer). It is thus unlikely that the event corresponding to wave 1 loaded the structure far in its non-linear structural response domain with significant effects of existing or progressing damage to the masonry.

The average $16.57 \mathrm{~Hz}$ for the second mode of the lighthouse, determined with a seismograph in 2013/2014 [52, 53] and the value of $15.9 \mathrm{~Hz}$ obtained by Loraux [21] in his FEM analyses (for an elastic modulus of the masonry of $10 \mathrm{GPa}$ ) do not appear in the accelerometer spectral analyses of the present study.

Figure 14 presents the results of the analyses for the signals before and during wave 1 event for accelerometer 4 , axes $\mathrm{x}$ and $\mathrm{y}$, after filtering with a high pass order 3 Butterworth filter cut-off at $1 \mathrm{~Hz}$. The trends are similar to that observed for the three other accelerometers, with a clearer signature of the first peak $(3.662 \mathrm{~Hz})$ of the structure, during the wave event.
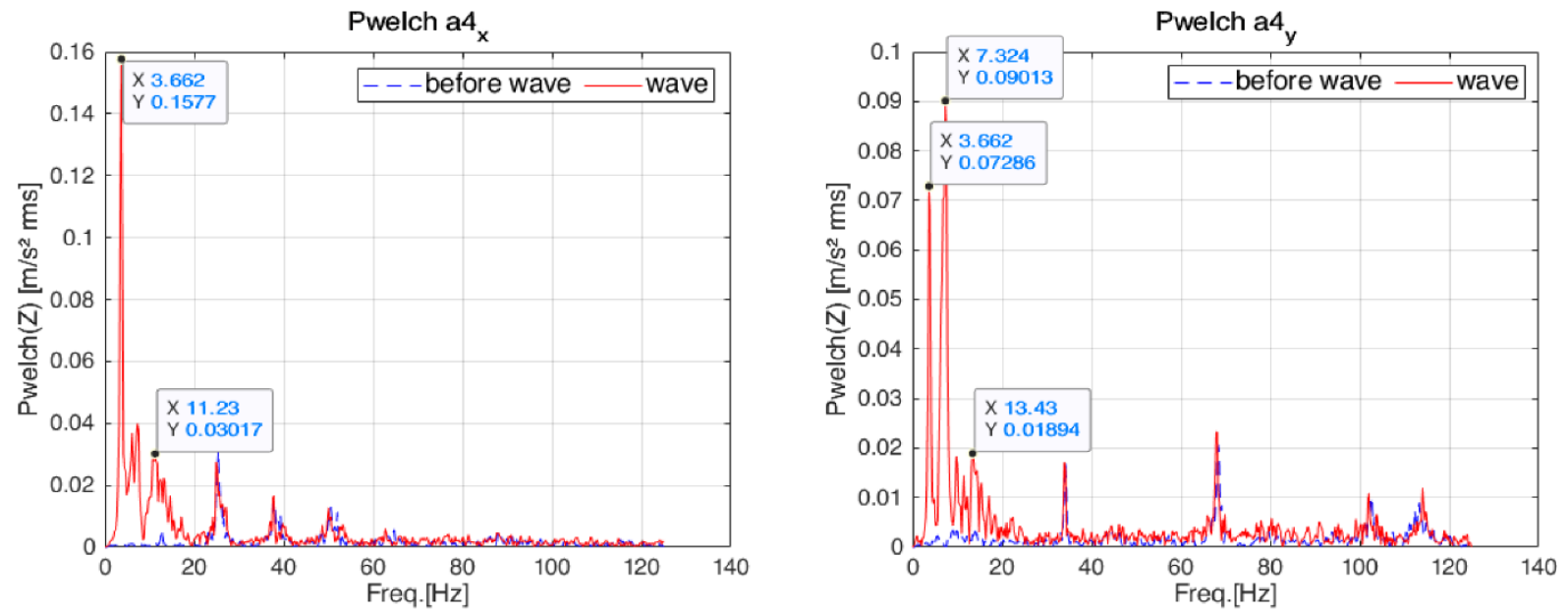

Figure 14. Analysis of accelerometer data for a4 (horizontal plane), rms spectral density vs frequency. Note the use of different vertical scales.

Finally, to determine a likely average cardinal orientation of the line along which the incoming wave impulse acted, a stepwise rotation was applied to each of the accelerometer signals (horizontal plane) to determine the rotation angle for which the maximum value of the first frequency peak (between 3.66 and $3.9 \mathrm{~Hz}$ corresponding to the expected first mode of vibration of the lighthouse) was obtained. The results of these calculations are summarised in Figure 15, with the orientation of the lines corresponding to the maximisation of the first frequency peak. The analysis of the signals of accelerometer 1, 2 and 3 for both horizontal axes show a similar trend of a likely impulse axis.

The direction of the impulse cannot be retrieved with this method. However, considering the direction of the swell and the photographic documentation, a direction from the third quadrant to the first is the only one possible. This confirms the major direction of impulse from accelerometer data as from Southwest to Northeast, with a wave likely to hit on face 5, or slightly shifted to face 4 , of the octagonal lighthouse tower. The analysis of data from accelerometer 4 gives a similar trend shifted towards the South. 


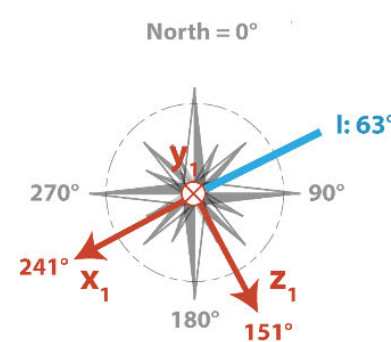

Accelerometer $\mathbf{n}^{\circ} \mathbf{1}$

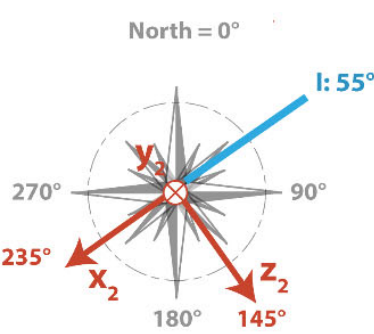

Accelerometer $\mathbf{n}^{\circ} \mathbf{2}$

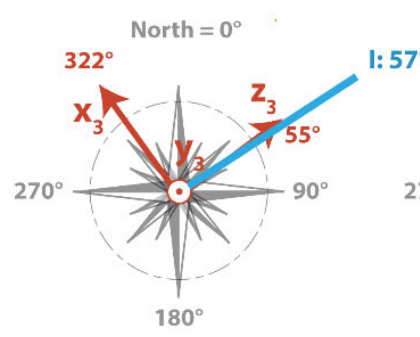

Accelerometer $n^{\circ} 3$

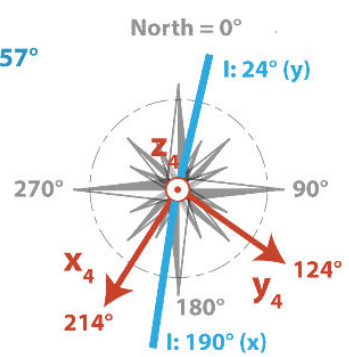

Accelerometer $n^{\circ} \mathbf{4}$

Figure 15. Orientation of the accelerometers and direction of maximal power density 'l' for the first eigenfrequency of the lighthouse, for each axis (similar results for axes $x$ and $z$ of accelerometers $1,2,3$ ).

The accelerations recorded for all vertical axes of the sensors are presented on Figure 16, after filtering with a high pass order 3 Butterworth filter cut-off at $1 \mathrm{~Hz}$ (the effect of gravity has been offset by subtracting the mean value of their accelerations from all measurements). Accelerometer a 2 shows a significant effect of event 2 , and $\mathrm{a} 3$ and 44 respond to event 1 of wave1.
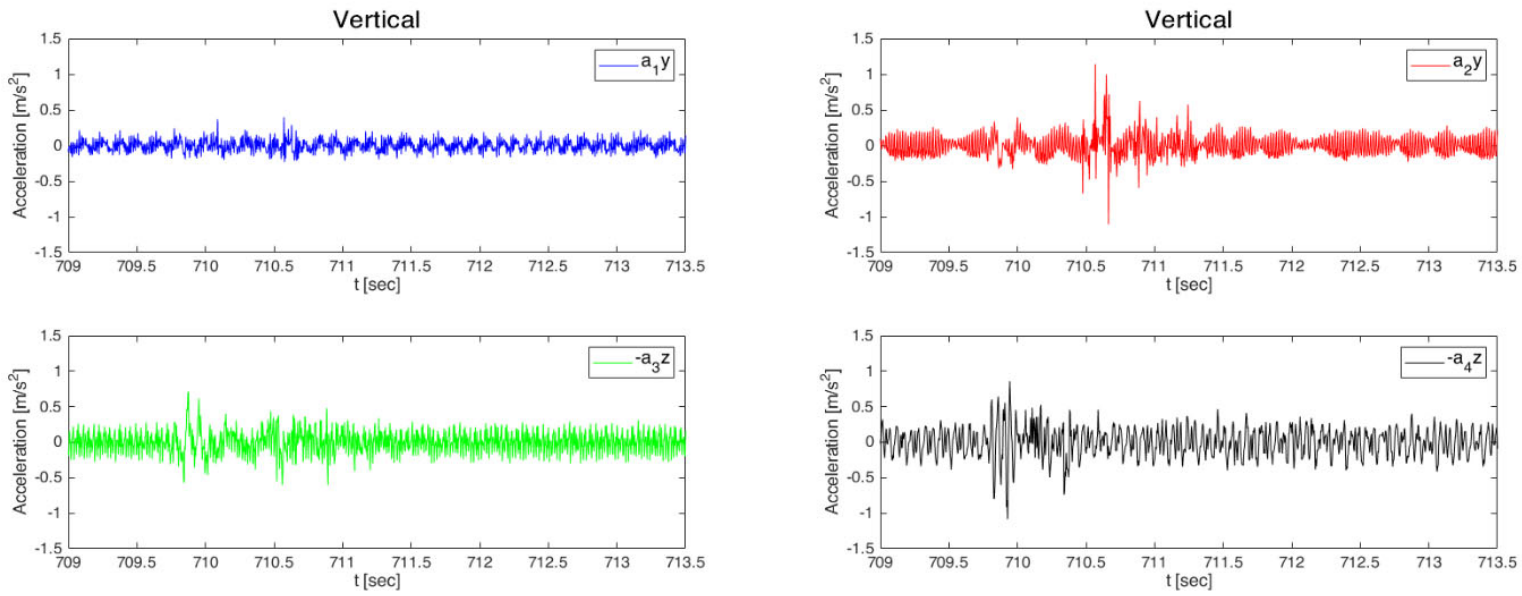

Figure 16. Raw accelerometer measurements (vertical direction) during wave1 event.

RMS spectral density vs frequency analyses were also performed for the signals corresponding to the vertical axes of the accelerometers, after filtering with a high pass order 3 Butterworth filter cut-off at $1 \mathrm{~Hz}$. The first frequency peak of the structure $(3.66 \mathrm{~Hz})$ appeared for all accelerometers except $\mathrm{n}^{\circ} 4$ which showed however a first peak at $1.7 \mathrm{~Hz}$. This effect is likely to be related to the fact that this accelerometer is not attached to the masonry structure, in the vertical direction.

\subsection{Determination of damping coefficient}

A damping coefficient was determined by means of visual fitting to the acceleration data (without filtering) of an exponential decay model (corresponding to searching for the logarithmic decrement) considering only one mode of vibration, with the first frequency peaks determined after $\S 4.5$. Equations (1.1) apply for $A_{d^{-}}$if $t>t_{0^{-}}$and for $A_{d}{ }^{+}$if $\mathrm{t}>\mathrm{t}_{0}{ }^{+}$. The parameters $a_{0, a m b}^{+} a_{0, a m b}^{-}$are the upper and lower bounds of ambient accelerations before the event, $a_{0}^{+}, a_{0}^{-}$are the positive, and negative scaling factors to fit to the starting point of the decay models, $f_{1}$ is the frequency and $\varsigma$ is the damping coefficient.

$A_{d}^{+}(t)=a_{0, a m b}^{+}+a_{0}^{+} \cdot e^{-2 \pi f_{1} \varsigma\left(t-t_{0}^{+}\right)}$
$A_{d}^{-}(t)=-a_{0, a m b}^{-}-a_{0}^{-} \cdot e^{-2 \pi f_{1} \varsigma\left(t-t_{0}^{-}\right)}$

Phil. Trans. R. Soc. A. 

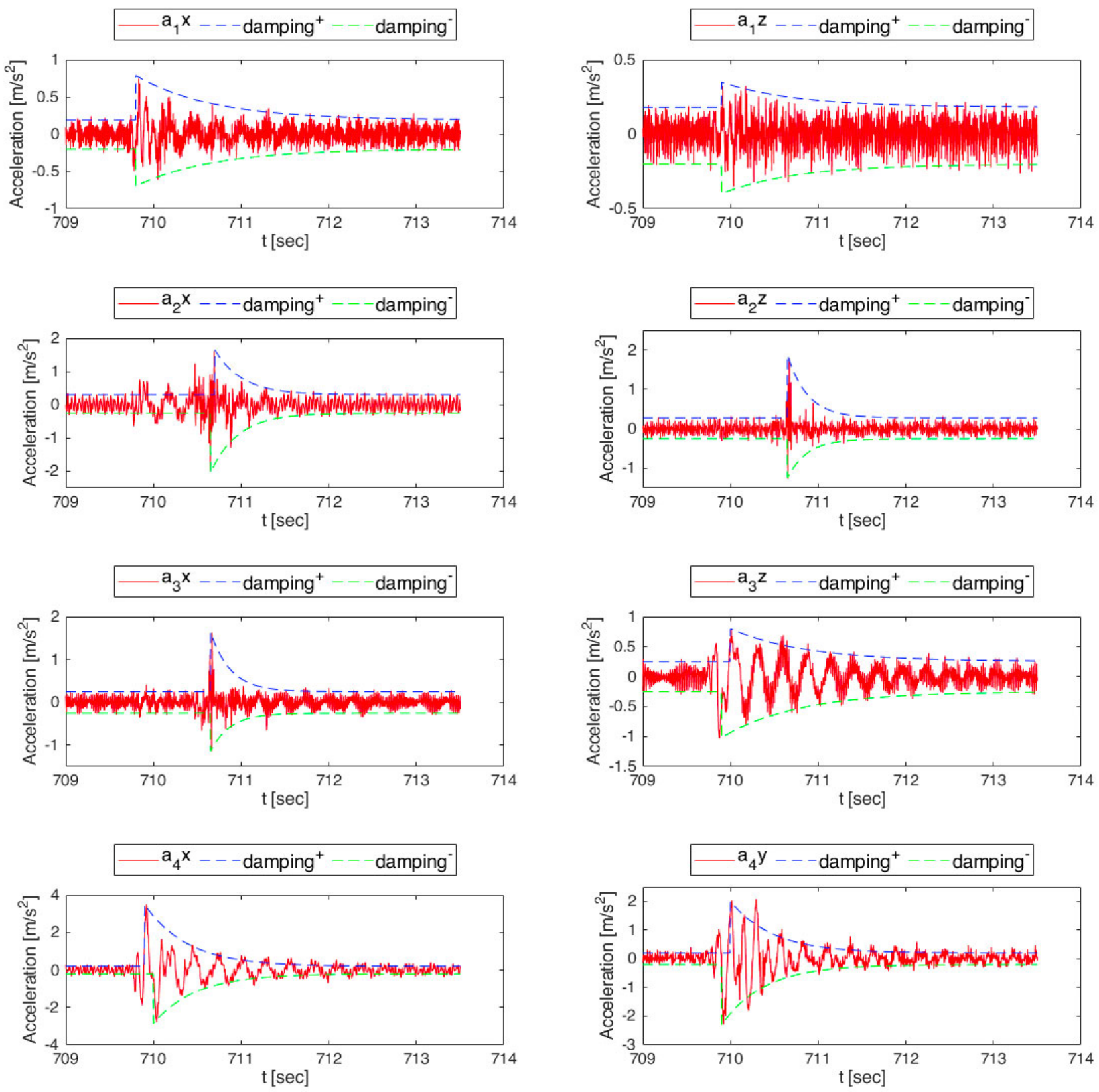

Figure 17. Exponential decay fitting to determine damping coefficients, for all accelerometers, horizontal axes. Note the use of different vertical scales.

For accelerometer 2, x-axis, an additional fitting was done with a starting point corresponding to event 1 , Figure 18. The response of this accelerometer, for this axis, is obviously a combination of two effects (events 1 and 2 already discussed before in §3.3).

Phil. Trans. R. Soc. A. 

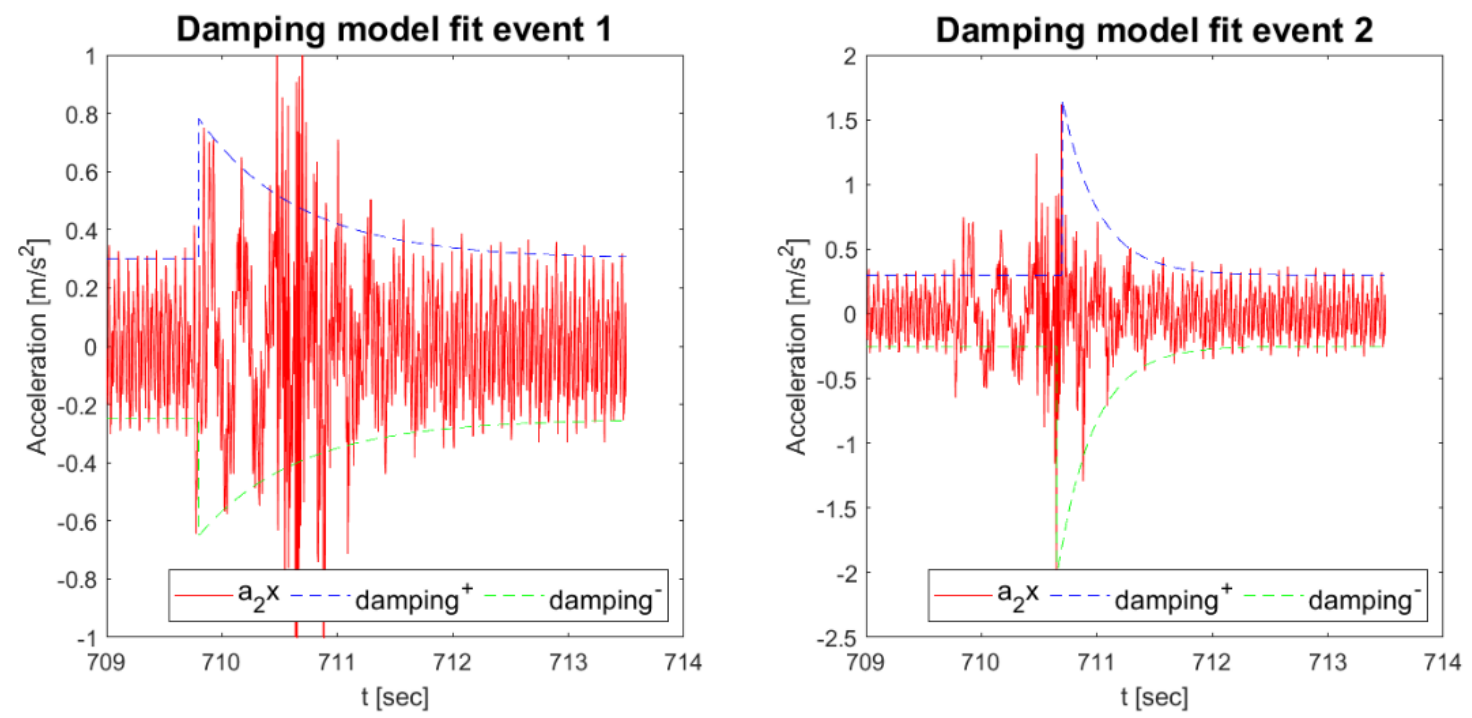

Figure 18. Exponential decay fitting to determine damping coefficients, for $a 2, x$ axis, for events 1 and 2 . Note the use of different vertical scales.

Table 2 summarises the parameters obtained from the fitting procedure. The analysis of measurements a1x, $\mathrm{a} 1 \mathrm{z}, \mathrm{a} 2 \mathrm{x}$ for fit event 1 , and a3z yields a damping coefficient of 0.05 , in agreement with what is expected for masonry structures. The fitting of data related to event 2 (Ref. a2x fit event 2, a2z and a3x according to Table 2) yields much higher values from 0.14 to 0.18 , likely to be related more to the special nature of this event than to the overall structural response of the lighthouse. Finally, the analysis of data for accelerometer 4 gives a damping coefficient of 0.09 for both axes, significantly higher than the 0.05 expected for the response of the masonry structure. This value is likely to be affected by the location of this sensor attached to the metallic frame of the optics which is simply resting on its supports without being tightly attached to the masonry structure.

Table 2. Fitting parameters for exponential decay model, all accelerometers (horizontal plane).

\begin{tabular}{|c|c|c|c|c|c|c|c|c|}
\hline Ref. & $\begin{array}{l}\text { Freq. } \\
{[\mathrm{Hz}]}\end{array}$ & $\begin{array}{l}t_{0}^{+} \\
{[s]}\end{array}$ & $\begin{array}{c}\mathrm{a}_{0}{ }^{+} \\
{\left[\mathrm{m} / \mathrm{s}^{2}\right]}\end{array}$ & $\begin{array}{c}\mathrm{a}_{0}^{+} \mathrm{amb} \\
{\left[\mathrm{m} / \mathrm{s}^{2}\right]}\end{array}$ & $\begin{array}{l}\mathrm{t}_{0}^{-} \\
{[\mathrm{s}]}\end{array}$ & $\begin{array}{c}\mathrm{a}_{0^{-}} \\
{\left[\mathrm{m} / \mathrm{s}^{2}\right]}\end{array}$ & $\begin{array}{c}\mathrm{a}_{0}-\mathrm{amb} \\
{\left[\mathrm{m} / \mathrm{s}^{2}\right]}\end{array}$ & $\begin{array}{c}\text { Damping } \zeta \\
{[---]}\end{array}$ \\
\hline a1x & 3.66 & 709.80 & 0.60 & 0.19 & 709.80 & 0.50 & 0.20 & 0.05 \\
\hline a1z & 3.66 & 709.90 & 0.17 & 0.18 & 709.90 & 0.20 & 0.20 & 0.05 \\
\hline a2x fit event 1 & 3.66 & 709.80 & 0.48 & 0.30 & 709.80 & 0.40 & 0.25 & 0.05 \\
\hline a2x fit event 2 & 3.66 & 710.70 & 1.35 & 0.30 & 710.65 & 1.80 & 0.25 & 0.14 \\
\hline $\mathrm{a} 2 \mathrm{z}$ & 3.90 & 710.65 & 1.60 & 0.28 & 710.65 & 1.00 & 0.25 & 0.18 \\
\hline$a 3 x$ & 3.90 & 710.65 & 1.40 & 0.25 & 710.65 & 0.90 & 0.25 & 0.18 \\
\hline$a 3 z$ & 3.66 & 710.00 & 0.55 & 0.25 & 709.90 & 0.77 & 0.25 & 0.05 \\
\hline$a 4 x$ & 3.66 & 709.90 & 3.30 & 0.20 & 710.00 & 2.65 & 0.20 & 0.09 \\
\hline a4y & 3.66 & 710.00 & 1.80 & 0.20 & 709.90 & 2.10 & 0.20 & 0.09 \\
\hline
\end{tabular}

\section{Discussion}

\subsection{General}

All data from the accelerometers clearly shows the effect of two distinct events, with distinct signatures in terms of frequency spectrum and damping of the oscillatory signals. One starting shortly after 709.5 sec (event 1) and one taking place around $710.7 \mathrm{sec}$ (event 2). Event 1 is likely to correspond to the wave hitting the lighthouse base and the lower part of the tower, from a direction between Southwest (according to the accelerometer measurements) and West-Northwest (according to the photographic documentation). 
It induces synchronised accelerations, velocities and displacements in a South-West to North-East direction, corresponding to x-axes of accelerometers 1,2, 4 and z-axis of accelerometer 3 . The corresponding velocities follow the expected trend of increasing with the height (along the lighthouse tower vertical axis) of the sensor locations. A similar trend is observed for the displacements along a South-West to North-East direction with maximum values for accelerometer 4 of +1.8 to $-3.4 \mathrm{~mm}$. Event 1 also induces significant displacements for accelerometer 4, in a North-West to South-East direction (+ $1 \mathrm{~mm}$ to $-2 \mathrm{~mm})$. Event 2 induces similar effects for accelerometers 2 and 3, with displacements between +0.9 and $-0.5 \mathrm{~mm}$, also along a Northwest to Southeast direction. It is possible that event 2 occurred close to the location of accelerometer 3 , along the vertical axis of the lighthouse tower. This event delayed by around $1 \mathrm{~s}$ from the beginning of event 1 might be due to a secondary effect of water projections on the higher parts of the lighthouse tower. Note that the delay of $1 \mathrm{~s}$ corresponds to the time frame between pictures Figure 6b) and Figure 8a) on the one hand, and Figure 7a) and b) on the other hand, which show that the time for the water splashes to reach the upper part of the lighthouse is between 0.4 and $1.1 \mathrm{~s}$ since wave breaking onset. The differences in responses between accelerometer 2 and 3 could also be explained by their different locations in plane in the lighthouse tower. Accelerometer a2 is set halfway between the two panels of the double window, on face 1 of the octagonal tower whereas a3 is set on the wall at the corner of faces 5 and 6 . Finally, the vectors of the direction of impact of wave1 and spatial distribution of subsequent splashes hitting the lighthouse are likely to be oriented eccentrically with respect to the central axis of the lighthouse tower, thus inducing non-uniform bending effects.

The orientation of the wave(s) hitting the lighthouse, determined from the analysis of the accelerometer data and photographic documentation (from Southwest to West-Northwest) significantly differs from that determined with the stereo-video cameras [1], for the incoming wave. These cameras point to a location at least $50 \mathrm{~m}$ from the axis of the structure and suggest a wave approaching from the Northwest. This inconsistency highlights the complex wave transformations in the immediate surroundings of the structure during wave breaking.

\subsection{Comparison with 3D FEM modelling results}

Figure 19 illustrates the 3D FEM model from Loraux (described in more details in $\S 1$ ). Note that this model represents the lighthouse up to the level of accelerometer 3 (in the present study) only and that the results of this study use this point as basis of comparison. As such measurement data of accelerometer 4 in the present study cannot be compared with those of Loraux. The first frequency was determined for two conditions, both using an elastic modulus of $10 \mathrm{GPa}$ (a) before reinforcements, in its 1916 condition and (b) after reinforcements, in its current condition, including damage induced by successive wave actions. The values of this first frequency were $3.12 \mathrm{~Hz}$ and $3.87 \mathrm{~Hz}$ respectively. This corresponds well to the values derived from the acceleration measurements in the present study, § 3.4, (3.66 to $3.9 \mathrm{~Hz})$. The values of damping coefficients derived from the accelerations measurements of the present study, §3.5 (0.05 for data corresponding to event 1 for accelerometer attached to the masonry structure) also confirm the assumptions of Loraux in his FEM calculations (global value of 0.05 used for calculations of Rayleigh damping model parameters) [21].

Generally speaking, except for accelerometer 4 which shows significant accelerations and displacements, accelerometers 1 to 3 show modest amplitudes. Loraux [21] performed numerical simulations of the lighthouse dynamic response to a wave hitting perpendicularly to face 5 along the $x$-axis of the lighthouse tower. In comparison to his results, the maximal recorded accelerations at the location of accelerometer 3 remain small at around $\pm 1 \mathrm{~m} / \mathrm{s}^{2}$ in comparison to +15 to $-20 \mathrm{~m} / \mathrm{s}^{2}$ for the same point from the FEM calculation (current condition of the lighthouse, impulsive pressure application over $0.05 \mathrm{~s}$ ) for a wave of $20 \mathrm{~m}$ hitting the lighthouse at maximum high tide of $+8.2 \mathrm{~m}$. The same applies to the displacements obtained from the FEM simulations for location of accelerometer 3 ( +11 to $-9 \mathrm{~mm}$ ) compared to those obtained by double integration of accelerometer 3 data in the present study ( 0.9 to $-1.8 \mathrm{~mm}$ ). This difference can be explained by the local tide circumstances during January 3, 2018, at $9 \mathrm{~h} 42$ UTC a tide level of $+1.27 \mathrm{~m}$, instead of the maximum tide level of $+8.2 \mathrm{~m}$ mentioned by Ribière [38], and assumed by Loraux in his calculations, in addition to the slightly higher wave height of $20 \mathrm{~m}$.

Phil. Trans. R. Soc. A. 
Recent studies were dedicated to the structural response of (among others) the Eddystone [10, 11], Fastnet [8], and Wolf Rock $[12,37]$ offshore lighthouses along the UK coasts, with total height and mass in the same range as those of La Jument. These three lighthouses modal responses showed first modes between (on average) 4.38 $\mathrm{Hz}$ and $4.94 \mathrm{~Hz}$ compared to $3.66 \mathrm{~Hz}$ for La Jument in its current condition. This difference can be explained by the different types of structures, with a coarse concrete core surrounded by a stone masonry outer layer (both likely to be damaged) for la Jument, compared to a significantly stiffer structure of (at least partly) dovetailed stone blocks for the UK lighthouses. Measurements with geophones helped determine the displacements on Eddystone during the 2013/2014 winter storms [10]. The maximum measured horizontal displacement of 0.07 $\mathrm{mm}$ for a maximum wave height $\mathrm{H}_{\max }$ of $15.14 \mathrm{~m}$ (February 5, 2014) nearby the lighthouse was much smaller than those observed on la Jument during the January 3, 2018 storm (accelerometer a3, -1.9 to $1 \mathrm{~mm}$ at the top of the masonry tower). Acceleration measurements under wave impact on the Wolf Rock Lighthouse [12] during the winter storms of 2017/2018 showed values up to $2 \mathrm{~m} / \mathrm{s}^{2}$, comparable to those determined on La Jument during the January 3, 2018 events, for the accelerometers a2 and a3 attached to the masonry structure of the lighthouse tower (Figure 10).

Numerical simulations with FEM were also performed to model the response of the UK lighthouses under the action of waves. For Eddystone [11], with $12 \mathrm{~m}$ height of wave impact area, the maximum predicted horizontal displacement was $0.25 \mathrm{~mm}$, and waves above $17.5 \mathrm{~m}$ started to represent a risk of overturning of the lighthouse tower (with a conservative load reduction factor of 1.6). For Wolf Rock [12], a 250 years return period (2017) wave $\left(\mathrm{H}_{\mathrm{s}}=12.25 \mathrm{~m}\right.$, upper loading level: $+17.99 \mathrm{~m}$, lower loading level: $\left.+9.28 \mathrm{~m}\right)$ induced a maximum horizontal tower displacement of $223 \mathrm{~mm}$. This displacement is much higher than those determined by Loraux in his FEM simulations of La Jument $( \pm 10 \mathrm{~mm})$, under the action of an extreme $20 \mathrm{~m}$ high wave hitting the lighthouse, at the maximum high tide of $+8.2 \mathrm{~m}$. For Fastnet [8], the 3D FEM simulations with a wave corresponding to $\mathrm{H}_{\mathrm{s}}=16$ $\mathrm{m}$, upper loading level: $+13.6 \mathrm{~m}$ (still on the base), lower loading level: $+7.35 \mathrm{~m}$, yielded maximum horizontal tower displacements of $0.7 \mathrm{~mm}$. The base of this lighthouse is however partly clinging to the rock which helps transmit the loads directly to the reef, thus limiting the action effects on the tower.

All these differences highlight the importance of the numerous factors of influence on the structural response of offshore lighthouses under wave actions: mode of construction and materials, slenderness, partial lateral support provided by nearby rocks, and wave action itself in terms of height, tide conditions, breaking mode, zone of application and pressures distribution along the lighthouse tower.

Wave1, although significant in terms of wave height (total of $19 \mathrm{~m}$ ) mostly hit the base of the La Jument lighthouse. Its crest is likely to have reached only the upper level of the reinforced concrete ring with limited effect on the structural response of the tower. Testimonies from archives [55] also support this fact. In a letter from 1930, following severe storms, engineer Quemeneur stated (translated from French): "...Dangerous oscillations for the optics take place only by severe storms from WNW to South, in two different ways: 1) WNW to SSW: oscillations with very rough sea and when waves pass minimum 3 to $4 \mathrm{~m}$ higher than the top of the base platform. As long as waves do not reach the platform, the lighthouse does not shake. As such, shakings are to fear around high tide; (2) SSW to $S$ : this is the most dangerous sector, although the sea is never very rough from this side. Shakings seem to be due to the irregular shape of the bedrock platform under the lighthouse, curved below the foundation and nearby a shoal where the waves rise before hitting the lighthouse. Oscillations turn out to appear mostly at low tide, with very strong wind, even if the sea is not furious, the swell passing or not above the base platform...". The storms of winter 2013/2014 that left the base of La Jument lighthouse with significant damage were much more severe than the events recorded on January 3, 2018.

Finally, a very strong assumption of the FEM calculations performed by Loraux [21] was the wave loading time sequence and their local pressure intensities. Various hypotheses were tested with different durations of impulsive loading from 0.001 to $0.1 \mathrm{sec}$. The difference in predicted accelerations and displacements of the top part of the masonry tower was very significant for different impulsive loading times. For $0.05 \mathrm{sec}$ the extreme values of acceleration and displacement were +20 to $-15 \mathrm{~m} / \mathrm{s}^{2}$, resp. around $\pm 10 \mathrm{~mm}$, whereas for $0.1 \mathrm{sec}$. they were $\pm 7 \mathrm{~m} / \mathrm{s}^{2}$, resp. -10 to $+22 \mathrm{~mm}$. This highlights the need for additional measurements of local pressures and wave loading time sequences, using piezometers installed on the base and tower faces. Note that this additional monitoring is foreseen and will hopefully soon be installed on La Jument lighthouse, with as many sensors as the project budget permits.

Phil. Trans. R. Soc. A. 


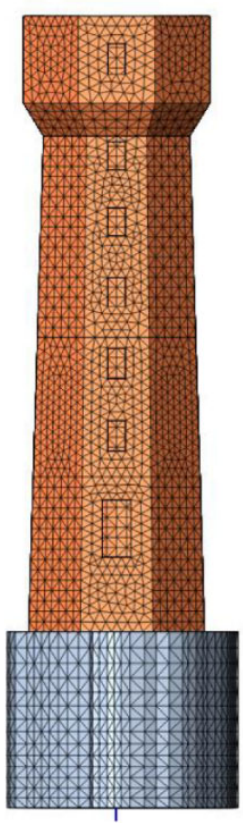

1

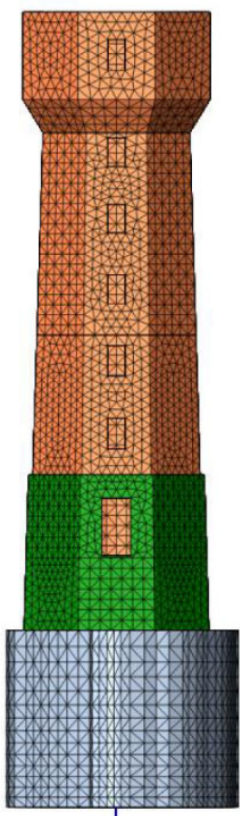

2

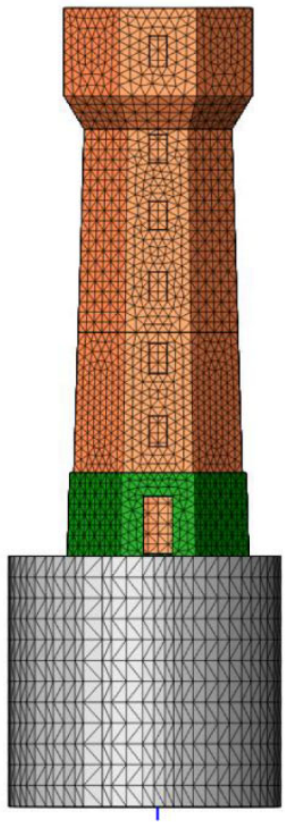

3

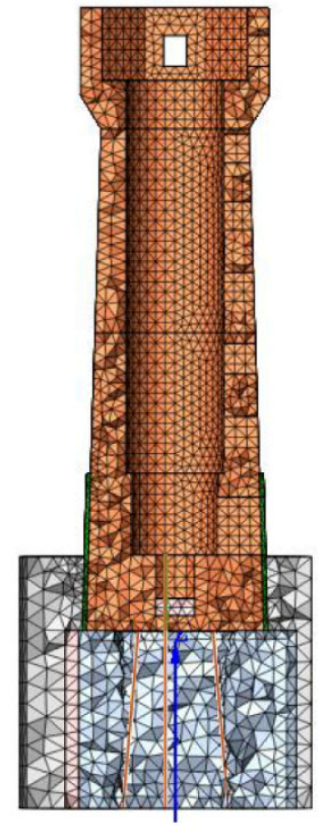

4

Figure 19. La Jument lighthouse, 3D finite element modelling of the successive steps of the life of the structure: (1) original condition (1911), (2) reinforced concrete strapping at the foot of the lighthouse and reinforcement of the tank (1917-18), (3) successive enlargements and base elevation (1919-1928), (4) 3 prestressed anchors (1936-1941), taken from Loraux [21].

\section{Conclusions}

- The structural response of La Jument lighthouse has been characterised by means of accelerometers during the impact of a breaking wave, on January 3, 2018.

- For the first time, a simultaneous photographic documentation of the same event, taken from two different locations on the Ushant island, helped determine a likely orientation of the wave from WNW and the position of its crest along the vertical axis of the lighthouse tower, just reaching the top of the reinforced concrete ring around the lower part of the tower.

- The analysis of the measurement data showed a consistent distribution of measurement values in terms of accelerations, velocities and displacements along the tower vertical axis.

- The first mode of the structural response as well as the apparent damping coefficient corresponded well with other data from literature and confirmed the hypotheses and findings of the 3D Finite element model of Loraux.

- The comparison of the maximum horizontal displacements observed or predicted by means of 3D FEM models, for different offshore lighthouses in UK and for la Jument, showed extreme differences. This highlights the importance of the numerous factors of influence on the structural response of offshore lighthouses under wave actions: mode of construction and materials, slenderness, partial lateral support provided by nearby rocks, and wave action itself in terms of height, tide conditions, breaking mode, zone of application along the lighthouse tower, and pressures distribution.

\section{Acknowledgements}

The authors wish to thank: (1): Christophe Loraux and Olivier Chollet (former MCS Master Students) for their motivation in working on Brittany lighthouses during their Master projects and the excellent results they achieved, (2) Archives départementales de Quimper, (3) Dominique Baot for his pictures of La Jument during the January 3, 2018 storm, (4), Michel Cloâtre for his advice and archive documents on La Jument, (5) George Pennec for his picture of la Jument at very low tide, (6) Nicolas Loix (micromega-dynamics), for his advice on the processing of accelerometer data. 


\section{References}

1. Filipot J-F, Guimaraes P, Leckler F, Hortsmann J, Carrasco R, Leroy E, et al. La Jument Lighthouse: a real scale laboratory for the study of giant waves and of their loading on marine structures. Phil Trans $R$ Soc A. 2019; submitted for publication, same issue.

2. Filipot J-F, Varing A, Duarte R, Leckler F, Guimaraes P, Gouin M, et al. The DiMe project : improving extreme sea states and wave breaking characterization for the design of MRE systems. In: Lafosse M, Laumone C, Peseux S, editors. ICOE 2018; June 12 th to June 14 ${ }^{\text {th }}$ 2018; Cherbourg, France: ICOE; 2018.

3. Fady N, Gallier S, Leroy E, Filipot J-F. Comportement dynamique des phares en mer - Instrumentation du phare de la Jument. JNM 2018 - Secondes Journées nationales maçonnerie IFSTTAR - Marne-la-Vallée 2018.

4. Nicolae Lerma A, Bulteau T, Lecacheux S, Idier D. Spatial variability of extreme wave height along the Atlantic and channel French coast. Ocean Engineering. 2015; 97:175-85.

5. Lerma AN, Bulteau T, Lecacheux S, Idier D. Période de retour des évènements de fortes houles le long des côtes françaises (Atlantique et Manche). In: Paralia, editor. XIIlèmes Journées Nationales Génie Côtier - Génie Civil; Dunkerque 2014.

6. Bulteau T, Lecacheux S, Lerma AN, Paris F, editors. Spatial extreme value analysis of significant wave heights along the French coast. International short conference on advances in extreme value analysis and application to natural hazards: EVAN2013; 2013.

7. McAllister M, Draycott S, Adcock T, Taylor P, Van Den Bremer T. Laboratory recreation of the Draupner wave and the role of breaking in crossing seas. Journal of Fluid Mechanics. 2019; 860:767-86.

8. Antonini A, Raby A, Brownjohn JMW, Pappas A, D'Ayala D. Survivability assessment of fastnet lighthouse. Coastal Engineering. 2019; 150:18-38.

9. Hu ZZ, Mai T, Greaves D, Raby A. Investigations of offshore breaking wave impacts on a large offshore structure. Journal of Fluids and Structures. 2017; 75:99-116.

10. Raby A, Bullock GN, Banfi D, Rafiq Y, Cali F. Wave loading on rock lighthouses. Proceedings of the Institution of Civil Engineers - Maritime Engineering. 2016; 169(1):15-28.

11. Trinh Q, Raby A, Banfi D, Corrado M, Chiaia B, Rafiq Y, et al. Modelling the Eddystone Lighthouse response to wave loading. Engineering Structures. 2016; 125:566-78.

12. Raby AC, Antonini A, Pappas A, Dassanayake DT, Brownjohn JMW, D'Ayala D. Wolf Rock lighthouse: past developments and future survivability under wave loading. Phil Trans R Soc A. 2019; submitted for publication, same issue.

13. Chollet O. Phare d'Ar-Men, Modélisation des effets de la houle, analyse du comportement structural et études de renforcement. Master thesis. Lausanne: EPFL; 2014.

14. TU Delft. SWASH - Simulating WAves till SHores: Delft University of Technology; 2019; available from: https://www.tudelft.nl/citg/over-faculteit/afdelingen/hydraulic-engineering/sections/environmentalfluid-mechanics/research/swash/.

15. Gentile C, Saisi A. Ambient vibration testing of historic masonry towers for structural identification and damage assessment. Construction and Building Materials. 2007; 21(6):1311-21.

16. Peña F, Lourenço PB, Mendes N, Oliveira DV. Numerical models for the seismic assessment of an old masonry tower. Engineering Structures. 2010; 32(5):1466-78.

17. Russo G, Bergamo O, Damiani L, Lugato D. Experimental analysis of the "Saint Andrea" Masonry Bell Tower in Venice. A new method for the determination of "Tower Global Young's Modulus E". Engineering Structures. 2010; 32(2):353-60.

18. Milani G, Valente M. Numerical insight into the seismic behavior of eight masonry towers in Northern Italy: FE pushover vs non-linear dynamic analyses. AIP Conference Proceedings. 2015; 1702(1):1600061-4.

19. Popko W. Comparison of Full-Scale and Numerical Model Dynamic Responses of Norströmsgrund Lighthouse. In: Yeung R, Rodier D, Oakley OH, editors. ASME $201433^{\text {rd }}$ International Conference on Ocean, Offshore and Arctic Engineering; San Francisco, California, USA. New York, NY American Society of Mechanical Engineers, Ocean, Offshore, and Arctic Engineering Division; 2014. p. V010T07A21.

20. Nord TS, Øiseth O, Lourens E-M. Ice force identification on the Norströmsgrund lighthouse. Computers E Structures. 2016; 169:24-39.

21. Loraux C. Comportement structural des phares en mer, étude historique sur le phare de la Jument et propositions d'interventions. Master thesis. Lausanne: EPFL; 2013.

22. DIANA. DIANA FEM analysis, ver. 9.4.4 2013; available from: https://dianafea.com/. 
23. Hordijk DA. Local approach to fatigue of concrete. Doctoral thesis: TU Delft; 1993.

24. Cornelissen H, Hordijk D, Reinhardt H. Experimental determination of crack softening characteristics of normalweight and lightweight. Heron. 1986; 31(2):45-56.

25. Lourenço PB, Rots JG, Blaauwendraad J. Continuum model for masonry: parameter estimation and validation. ASCE Journal of structural engineering. 1998; 124(6):642-52.

26. Morison JR, Johnson JW, Schaaf SA. The Force Exerted by Surface Waves on Piles. SPE-950149-G. 1950; 2(05):149-54.

27. Von Karman T. The impact on seaplane floats during landing. NACA technical notes. 1929; ( $\left.\mathrm{N}^{\circ} 321\right)$.

28. Goda Y, Haranaka S, Kitahata M. Study on impulsive breaking wave forces on piles. Port and HarbourTechnical Research Institute; 1966.

29. Goda Y. Random Seas and Design of Maritime Structures. 3rd Edition ed: World Scientific; 2010.

30. Wienke J, Sparboom U, Oumeraci H. Breaking Wave Impact on a Slender Cylinder. In: Edge BL, editor. 27th International Conference on Coastal Engineering 2000. p. 1787-98.

31. Wienke J, Oumeraci H. Breaking wave impact force on a vertical and inclined slender pile - theoretical and large-scale model investigations. Coastal Engineering. 2005; 52(5):435-62.

32. Zhou D, Chan ES, Melville WK. Wave impact pressures on vertical cylinders. Applied Ocean Research. 1991; 13(5):220-34.

33. CETMEF, EDF-LNHE. ANEMOC - Atlas Numérique d'Etats de mer Océanique et Côtier 2019; available from: http://anemoc.cetmef.developpement-durable.gouv.fr/.

34. CETMEF. CANDHIS - Centre d'Archivage National de Données de Houle In Situ 2019; available from: http://candhis.cetmef.developpement-durable.gouv.fr/.

35. Denarié E, Jacomo D, Fady N, Corvez D. Rejuvenation of maritime signalisation structures with UHPFRC. In: Toutlemonde F, Resplendino J, editors. UHPFRC 2013, $2^{\text {nd }}$ International Symposium on Ultra-High Performance Fibre-Reinforced Concrete, (UHPFRC); Marseille: RILEM; 2013. p. 157-66.

36. Banfi D. A field and laboratory study on the dynamic response of the Eddystone lighthouse to wave loading. Doctoral thesis: University of Plymouth; 2018.

37. Brownjohn JMW, Raby A, Bassitt J, Antonini A, Hudson E, Dobson P. Experimental modal analysis of British rock lighthouses. Marine Structures. 2018; 62:1-22.

38. Ribière C. Construction du phare de la Jument d'Ouessant. Annales des Ponts et Chaussées. 1911; 11:408-

17.

39. A_25S_0466. Exécution des travaux. - Prises de vues photographiques a differentes étapes de construction : 46 photographies. Archives Départementales de Quimper; 1906-1911.

40. Géoportail. Ouessant, Phare de la Jument, satellite picture, scale: 1:266, access date: March 122019 ; available from: https://www.geoportail.gouv.fr/.

41. A_25_S_484. Consolidation du phare. - Projet : correspondance, demande, détail estimatif, avant-métré des travaux, plans. Archives Départementales de Quimper; 1918.

42. A_25S_0474_001. Tour du phare de La Jument d'Ouessant. - Echelle de 0,01 pour 1 mètre. 1 plan, 2 coupes horizontale et verticale, 2 élévations sur 1 feuille : crayon, papier ; 62,3 x 62,8 cm, avec annotations sur projet élargissement soubassement. Archives Départementales de Quimper; 1904-1911.

43. Thauvin B. Expertise du phare de la Jument, Synthèse, Analyse des documents d'archives et proposition de suite à donner. CETE Ouest - LRPC St Brieuc; 2011. Contract No. 14792.

44. Manhaval B, Richard M. Phare de la Jument - Étude dynamique. Rapport de stage. Nantes: CETE Ouest; 2012.

45. Denarié E. Wave hitting la Jument Lighthouse, january 3, 2018, 9 h 42 UTC, pictures taken from Pern, Ushant. Morges 2018.

46. Baot D. Wave hitting la Jument Lighthouse, january 3, 2018, 9 h 42 UTC, pictures taken from Porzh Doun, Ushant. Ushant 2018.

47. SHOM. Map Île Molène, île d'Ouessant, passsage du Fromveur, scale: 1:20,000: Service hydrographique et océanographique de la marine (SHOM); 2019; available from: https:/ / diffusion.shom.fr/.

48. Ardhuin F. Position de la surface de la mer par rapport au niveau moyen - du goulet de Brest à Portsall, île d'Ouessant: $\quad$ IFREMER; $2019 ; \quad$ available from: https://marc.ifremer.fr/resultats/niveaux/modeles_mars2d_atlantique_nord_est/(typevisu)/map/(zoneid) /7066\#арpTop.

49. Hahn B, Valentine DT. Essential MATLAB for Engineers and Scientists: Newnes; 2007.

50. Matlab. Welch's power spectral density estimate, pwelch, R2018b 2019; available from: https://ch.mathworks.com/help/signal/ref/pwelch.html. 
51. Welch P. The use of fast Fourier transform for the estimation of power spectra: A method based on time averaging over short, modified periodograms. IEEE Transactions on Audio and Electroacoustics. 1967; 15(2):70-3. 52. Loraux C. Campagne de mesure sur les phares de la Jument et du Creach, mesure des vibrations ambiantes et relevé de l'état (Jument seulement). EPFL; 2013. Report no. MCS 23.13.09-1.

53. Chollet O. Campagne de mesure sur les phares de la Jument et du Creach, mesure des vibrations ambiantes, mars 2014. EPFL; 2014. Report no. MCS - Internal.

54. A_25_S_479. Equipement d'un oscillographe graphique. - Mesures des oscillations de la tour 1917-1941: correspondance, rapports de l'ingénieur des TPE, notes, graphiques. Archives Départementales de Quimper; 1935 and 1939.

55. A_25_S_478. Tempête. - Réparations : correspondance, rapports de l'ingénieur, sous-ingénieur subdivisionnaire et du subdivisionnaire, plans, lettre du 30 Avril 1930, envoyée par Quemeneur. Archives Départementales de Quimper; 1930.

Phil. Trans. R. Soc. A. 